San Jose State University

SJSU ScholarWorks

Master's Theses

Master's Theses and Graduate Research

Summer 2013

\title{
MASTERMIND-LIKE 1-Dependent Notch Target Gene Activation Requires a Sequence-Paired Site and a TATA Box
}

Cassandra Agbayani Ramos

San Jose State University

Follow this and additional works at: https://scholarworks.sjsu.edu/etd_theses

\section{Recommended Citation}

Ramos, Cassandra Agbayani, "MASTERMIND-LIKE 1-Dependent Notch Target Gene Activation Requires a Sequence-Paired Site and a TATA Box" (2013). Master's Theses. 4360.

DOI: https://doi.org/10.31979/etd.rh9z-z2ej

https://scholarworks.sjsu.edu/etd_theses/4360

This Thesis is brought to you for free and open access by the Master's Theses and Graduate Research at SJSU ScholarWorks. It has been accepted for inclusion in Master's Theses by an authorized administrator of SJSU ScholarWorks. For more information, please contact scholarworks@sjsu.edu. 


\title{
MASTERMIND-LIKE 1-DEPENDENT NOTCH TARGET GENE ACTIVATION REQUIRES A SEQUENCE-PAIRED SITE AND A TATA BOX
}

\author{
A Thesis \\ Presented to \\ The Faculty of the Department of Biological Sciences \\ San José State University \\ In Partial Fulfillment \\ of the Requirements for the Degree \\ Master of Science
}

by

Cassandra Agbayani Ramos

August 2013 
(C) 2013

Cassandra Agbayani Ramos

ALL RIGHTS RESERVED 
The Designated Thesis Committee Approves the Thesis Titled

MASTERMIND-LIKE 1-DEPENDENT NOTCH TARGET GENE ACTIVATION REQUIRES A SEQUENCE-PAIRED SITE AND A TATA BOX

by

Cassandra Agbayani Ramos

APPROVED FOR THE DEPARTMENT OF BIOLOGICAL SCIENCES

SAN JOSÉ STATE UNIVERSITY

August 2013

Dr. Brandon White Department of Biological Sciences

Dr. Elizabeth Skovran Department of Biological Sciences

Dr. Brooke Lustig Department of Chemistry 


\title{
ABSTRACT \\ MASTERMIND-LIKE 1-DEPENDENT NOTCH TARGET GENE ACTIVATION REQUIRES A SEQUENCE-PAIRED SITE AND A TATA BOX
}

\author{
by Cassandra Agbayani Ramos
}

Notch signaling plays an important role in mammalian cellular proliferation, apoptosis, and differentiation. To activate target genes, the Notch intracellular domain (NICD) forms a complex with CBF1 and Mastermind-like protein (MAM). The Notch activation complex binds to a response element containing the consensus sequence RTGRGAR ( $\mathrm{R}=$ purine $)$ on target gene promoters. The promoter of one well characterized target gene, Hes1, contains four Notch response elements (NREs). Sitedirected mutagenesis and reporter gene assays were used to examine the activation of Hes1 by mutating individual and combinations of NREs. Results indicated that NREs 2 and 4 are important for Hes1 activity, confirming previous results that this sequencepaired site (SPS) is an important feature of Notch target genes. Orientation and spacing between elements on the SPS were mutated in these studies. Other mutations included the Hes1 TATA box and the spacing between the SPS and TATA box. Additionally, a charged residue on NICD was mutated; this residue is believed to be responsible for Notch complex dimers. These results showed that SPS spacing and orientation as well as dimerization of Notch complexes are important for the promoter activity of Hes1. The TATA box was found to be necessary for promoter activation, and this activity is independent of spacing between the SPS and TATA box up to 173 base pairs. Taken together, these findings suggest that NICD- and MAM-mediated activation of target genes requires orientation- and spacing-dependent SPS and TATA box elements. 


\section{ACKNOWLEDGMENTS}

I extend my deepest gratitude to my principal investigator and thesis advisor, Dr. Brandon White. I will always be grateful for the research opportunities he has given me. Working with Dr. White is a constant pleasure and I am proud to say that I have had an ideal M.S. program experience in his research laboratory. He has been an outstanding mentor, who has always pushed me to become a better scientist. I am grateful for all his helpful discussions, practice presentations, career advice, and generous support. Not only is Dr. White a wonderful advisor, but he is a deeply caring individual who has always been dedicated to my personal and professional growth.

I would also like to thank my thesis committee members, Drs. Elizabeth Skovran and Brooke Lustig. Their helpful comments, suggestions, and encouragement have been invaluable for my thesis progress. They have been a treasured support system for me as I complete my M.S. program.

I am also grateful for the wonderful collaboration and support from my fellow labmates: Dr. Elaina Chambers, Zackery Bevens, Anthony Bortolazzo, Christine Ha, Danny Ha, Asmara Hoo, Tetiana Lialiutska, Vy Ly, Nikki Nguyen, Anh Pham, Anh Truong, and Ivan Zein. I also extend my thanks to Thomas Burke, a former student in

Dr. White's lab, for creating the original Hes1 individual NRE site mutant plasmids used in my research.

I would like to acknowledge the SJSU Department of Biological Sciences Scholarship Committee for awarding me the Glenn and Martha Vargas Scholarship and 
Albert and Dorothy Ellis Fellowship. These funds have been greatly beneficial to my research progress.

I would also like to acknowledge the CSU Program for Education and Research in Biotechnology and the American Society for Biochemistry and Molecular Biology for awarding me travel grants. These awards allowed me to present my thesis work and communicate with scientists from around the world. This experience provided much professional development and many memorable experiences.

I owe many thanks to the wonderful professors who have helped me grow as a student and scientist through their classes: Drs. Luis Bonachea, Daniel Holley, Peter Nemes, Leslee Parr, Michael Sinensky, and Miri VanHoven.

Finally, I would like to thank my mom, Daniel, my family, and my friends for lending helping hands through difficult times and sharing laughs and smiles in times of celebration and triumph. Completing this thesis would not have been possible without their loving support. 


\section{DEDICATIONS}

This thesis is dedicated to my mom, Lorraine Agbayani. She is my personal hero and

lifelong teacher. Her immense courage, strength, and love are always my inspiration.

She reminds me that biomedical research is about helping the people that we hold dearest in our hearts.

This thesis is also dedicated to Daniel F. Coronado, my loving and supportive partner who makes every day feel like a dream come true. 


\section{TABLE OF CONTENTS}

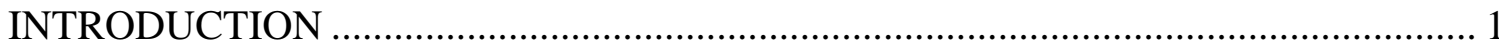

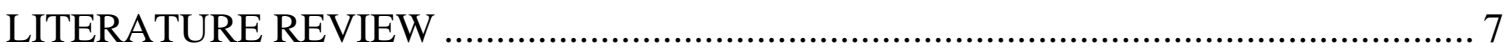

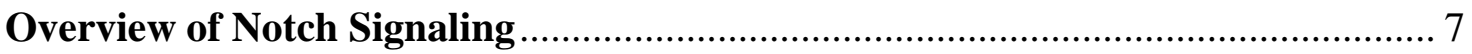

Overview of Transcription in Class II Promoters .......................................... 13

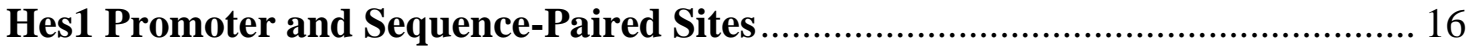

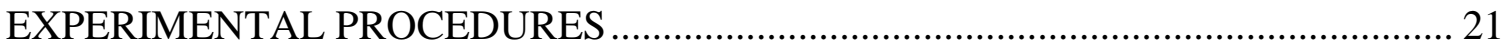

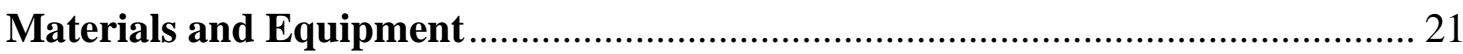

Generation of Mutant Plasmids by Site-Directed Mutagenesis ......................... 22

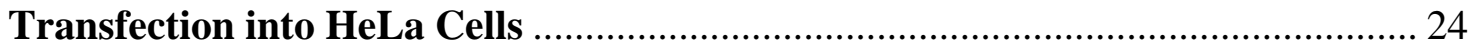

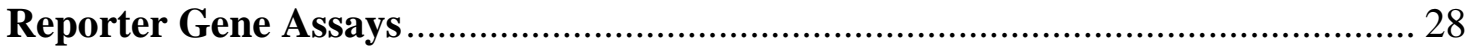

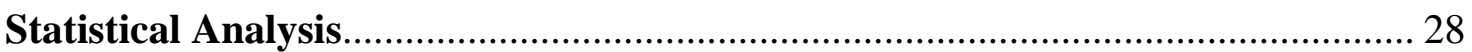

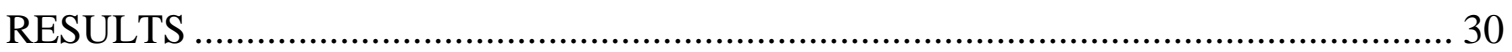

Activation of Hes1 with Notch 1 and Mastermind-like 1 ................................. 30

Notch 1- and Mastermind-like 1-Mediated Hes1 Activation with Mutated

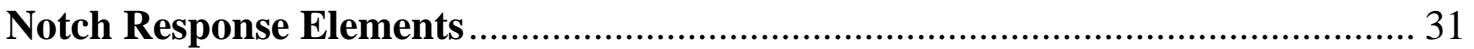

Hes1 Promoter Activity with a Notch Dimerization Mutant .............................. 32

Notch- and Mastermind-like-Mediated Activation of Hes1 with a Sequence-

Paired Site Separated by Additional Base Pairs ............................................... 33 
Notch- and Mastermind-like-Mediated Activation of Hes1 with Different

Orientations of the Sequence-Paired Site. 34

Notch- and Mastermind-like-Mediated Activation of Target Genes with a

Mutated TATA Box 36

Notch- and Mastermind-like-Mediated Activation of Hes1 with Altered Base

Pair Spacing between the Sequence-Paired Site and TATA Box 38

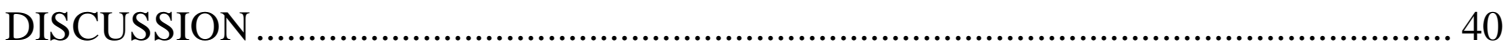

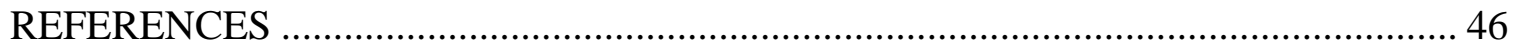




\section{LIST OF FIGURES}

FIGURE 1: Overview of Notch signaling ....................................................... 2

FIGURE 2: Model of transcription initiation by Notch complex ............................. 2

FIGURE 3: Hes1 gene fragment used for promoter analysis studies........................ 3

FIGURE 4: Crystal structure of Notch complex dimers assembled on the Hes1

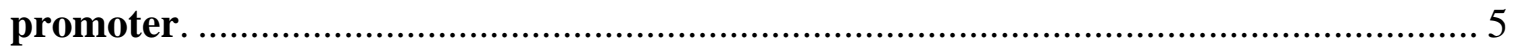

FIGURE 5: Hes1 promoter fragment used in reporter gene studies ....................... 25

FIGURE 6: Hes5 promoter fragment used in reporter gene studies ...................... 26

FIGURE 7: Fold promoter activities of Hes1 with N1ICD and MAM1 ................... 30

FIGURE 8: Activation of Hes1 NRE site mutants .............................................. 31

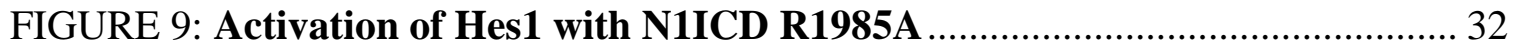

FIGURE 10: Activation of Hes1 with separated SPS elements ............................. 33

FIGURE 11: Activation of Hes1 SPS orientation mutants.................................... 35

FIGURE 12: Activation of Notch target genes with a mutant TATA box ................. 37

FIGURE 13: Activation of Hes1 with modified spacing between SPS and TATA

box

FIGURE 14: Proposed models of MAM-dependent Notch target gene activation.... 45 


\section{LIST OF TABLES}

TABLE 1: Reaction conditions for site-directed mutagenesis ............................... 2

TABLE 2: Thermal cycler conditions for site-directed mutagenesis reactions .......... 2

TABLE 3: Mutant promoter sequences............................................................ 7 


\section{ABBREVIATIONS}

Ac/Da: Achaete and Daughterless

ADAM: A Disintegrin And Metalloprotease

ANK: ankyrin

bHLH: basic helix-loop-helix

CBF: C-promoter binding factor

CBP: c-AMP response element binding protein

CDK: cyclin dependent kinase

CIR: CBF1 interacting corepressors

CREB: c-AMP response element binding protein

CSL: CBF1/Su(H)/Lag-1

DMEM: Dulbecco's modification of Eagle's medium

dNICD: Drosophila Notch intracellular domain

DSL: Delta/Serrate/LAG-2

EGF: Epidermal Growth Factor

EMSA: electrophoretic mobility shift assay

E(spl): Enhancer of split

GTF: general transcription factor

$\mathbf{H}_{\mathbf{0}}$ : null hypothesis

Hairy/Enhancer of Split: Hes

HD: Notch heterodimerization domain

HDAC: histone deacetylase 
LB: lysogeny broth

LNR: Lin12/Notch repeats

MAM: Mastermind-like protein

MAM1: Mastermind-like protein 1

mHes: mouse Hairy/Enhancer of Split

NECD: Notch extracellular domain

N1ICD: Notch1 intracellular domain

NICD: Notch intracellular domain

NRE: Notch response element

NRR: negative regulatory region

NT: NRE-to-TATA

NTM: Notch transmembrane subunit

NZY: NZ-amine and yeast

OFUT: O-fucosyltransferase

PCAF: p300/CBP-associated factor

PEST: proline, glutamate, serine, and threonine rich domain

RAM: Recombination Binding Protein-associated module

RNAPII: RNA polymerase II

SCF: S-phase kinase-association protein/Cullin/F-box

SEL10: Suppressor/Enhancer of lin-12 10

SHARP: SMRT/HDAC-1 Associated Repressor Protein

SKIP: Ski-interacting protein 
SMRT: Silencing Mediator of Retinoid and Thyroid hormone receptor

SPS: sequence-paired site

TACE: tumor necrosis factor- $\alpha$ converting enzyme

T-ALL: T-cell acute lymphoblastic leukemia

TAF: TBP-associated factor

TBP: TATA-binding protein

TE: Tris-EDTA

TFII: Transcription factor II

TSS: transcription start site 


\section{INTRODUCTION}

Notch is a transmembrane protein with an extracellular receptor used to communicate with adjacent cells (1). When the receptor binds to ligands from the Delta/Serrate/LAG-2 (DSL) family, there is a conformational change of Notch, allowing its cleavage by a gamma-secretase complex. This proteolytic cleavage releases the Notch intracellular domain (NICD), which translocates to the nucleus to bind to the promoters of target genes and initiate transcription (Fig. 1) (2, 3). In mammals, NICD binds to the transcription factor, C-promoter binding factor (CBF) 1, and the coactivator, Mastermind-like protein (MAM). This ternary complex binds to a Notch response element (NRE) containing the consensus sequence RTGRGAR (R=purine) on target gene promoters (4). This complex is essential for promoter activation. In mammals, there are four Notch proteins and three MAM proteins; however, it is still unclear how these homologs differentially modulate Notch signaling.

The Notch ternary complex recruits additional coactivators for transcription initiation. MAM recruits $\mathrm{p} 300$, a histone acetyltransferase, which is essential for transcription initiation (5). MAM also recruits cyclin dependent kinase (CDK) 8, as it is necessary for Notch turnover (6). CDK8 can associate with the Mediator coactivator complex, which recruits the basal transcription machinery. The working model of Notch and MAM mediated target gene activation postulates that Mediator is responsible for recruiting RNA polymerase II (RNAPII) in order to initiate transcription (Fig. 2) (6). 


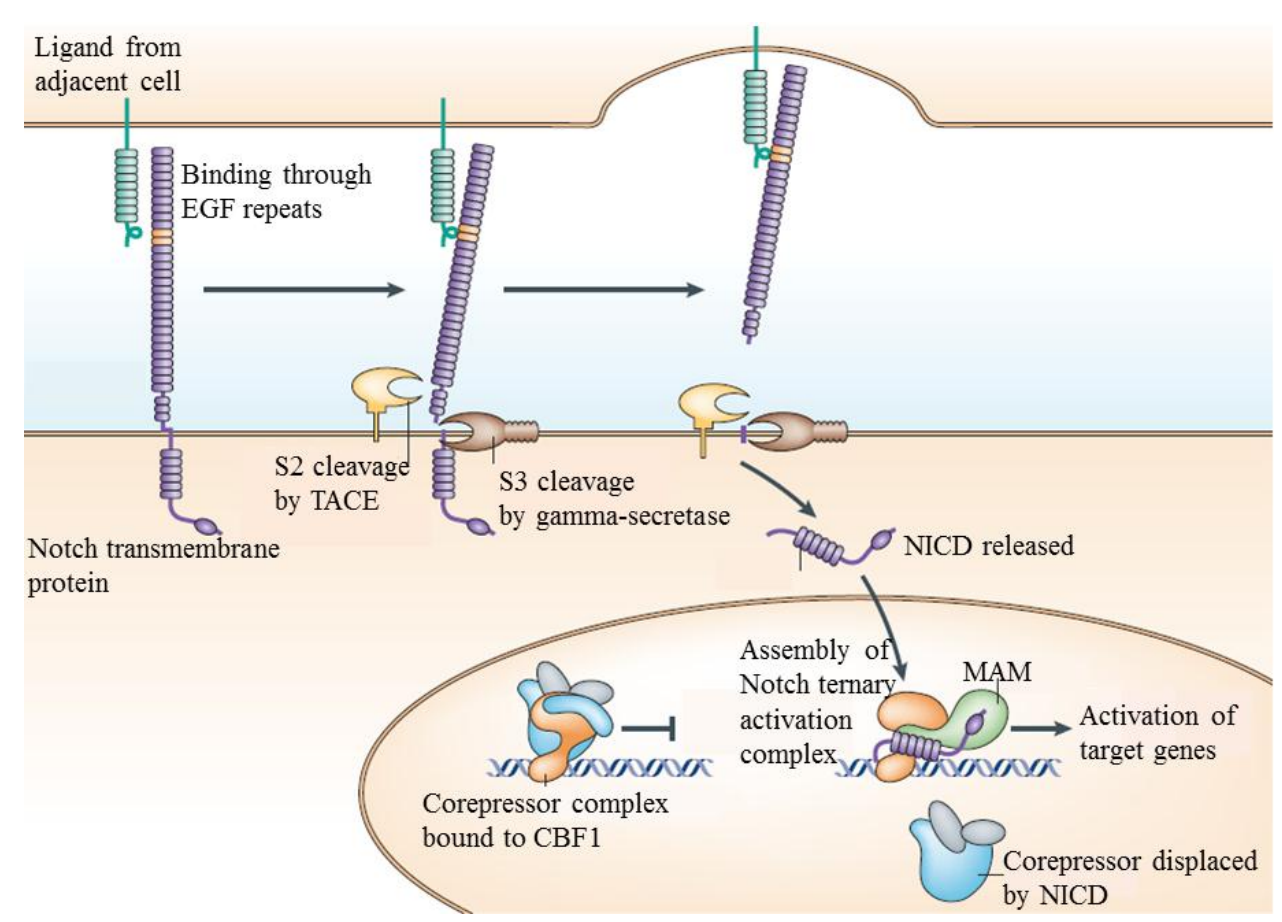

FIGURE 1: Overview of Notch signaling. The mature Notch transmembrane is cleaved after binding to ligands from the DSL family of proteins in adjacent cells. The NICD is released from the cell membrane and translocates to the nucleus. The assembly of NICD and MAM on CBF1 displaces a corepressor complex and activates target genes. Adapted by permission from Macmillan Publishers Ltd: Nat. Rev. Mol. Cell Biol. (3), copyright 2006.

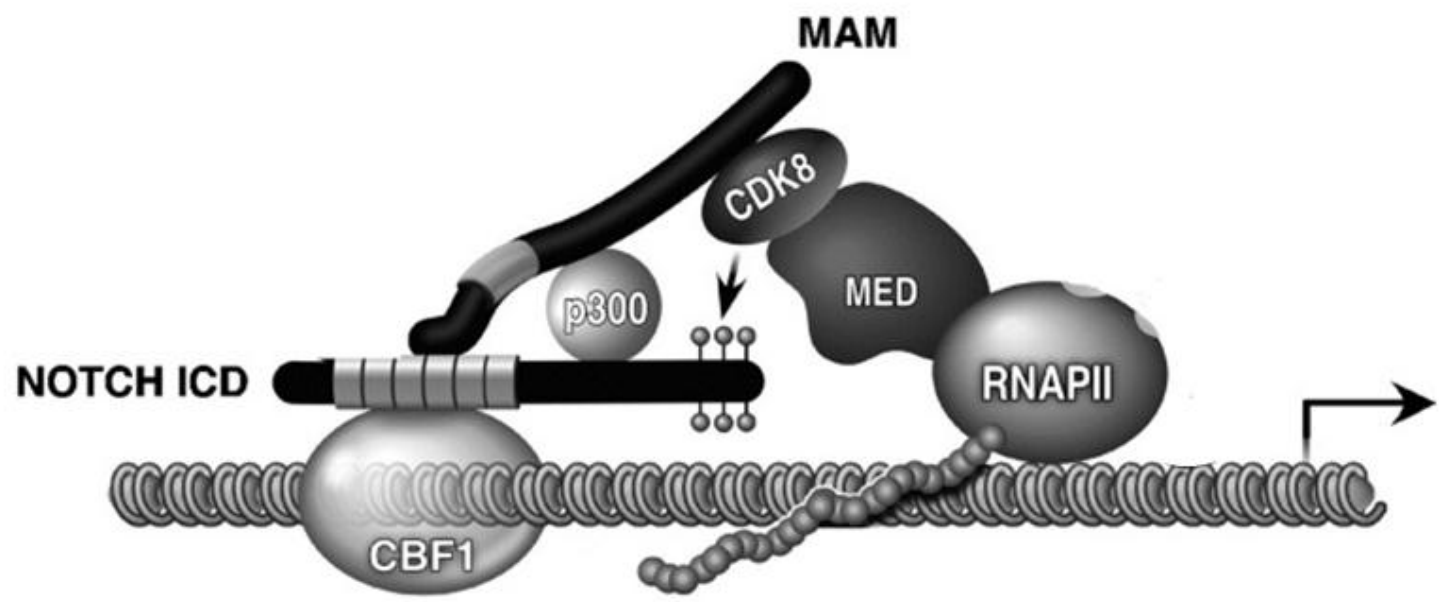

FIGURE 2: Model of transcription initiation by Notch complex. The Notch signaling complex binds to an NRE on target gene promoters. MAM recruits CDK8, which may recruit RNAPII through Mediator. Adapted by permission from Elsevier Ltd.: Mol. Cell (6), copyright 2004. 
In the studies presented here, Notch target genes were investigated by studying the promoter of mouse Hairy/Enhancer of Split (mHes) 1 (Fig. 3). mHes1 has over 95\% homology with the human Hes1 promoter. The mHes1 (hereinafter referred to as Hes1) promoter has four NREs, which are conserved in all vertebrates. Three of the Hes1 NREs have been studied by other research groups, whereas one NRE has not been investigated in previous literature until now (7-9). These NREs have a specific orientation depending on whether the consensus sequence is located on the forward or reverse strand of the promoter. NREs on the forward strand are designated as Head sites, whereas NREs on the reverse strand are Tail sites. The Hes1 promoter also has a putative TATA box, a region rich in thymines and adenines that binds to the Transcription Factor II (TFII) D complex. TFIID is a component of the pre-initiation complex that assembles the core transcription machinery. TFIID has been shown to recruit RNAPII to the promoter (10). The NRE-to-TATA (NT) region on the Hes1 promoter refers to the 24 base pairs between the NREs and the TATA box.

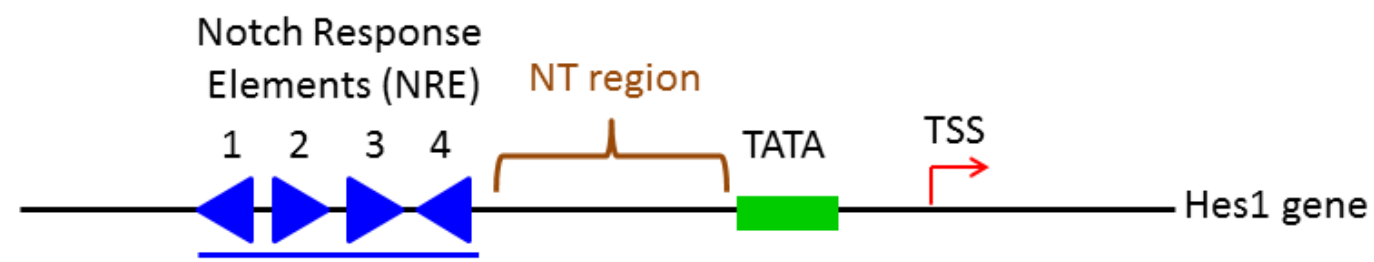

FIGURE 3: Hes1 gene fragment used for promoter analysis studies. Hes1 contains four Notch Response Elements (NREs) and a TATA box. The 24 base pairs between the NREs and the TATA box comprise the NT Region. Triangles pointing right signify a Head site and triangles pointing left signify a Tail site. TSS represents the transcription start site. 
Previous research groups have shown that two of the four NREs recruit Notch activation complexes that form a dimer, which is an essential element of transcription initiation of Hes1 $(8,9)$. NREs 2 and 4 comprise a sequence-paired site (SPS), a response element architecture for two transcription factors. The orientation of the NREs within the SPS is Head and Tail. The Notch dimer crystal structure was solved on a synthetic promoter, and this dimerization appears to depend on residue 1985 in the ankyrin (ANK) domain of NICD (Fig. 4) (9, 11). A mutant form of NICD with this residue altered from an arginine to an alanine showed a decrease in Hes1 promoter activity compared to activity of wildtype NICD. In addition, altering the spacing and orientation of the SPS was shown to reduce dimerization activity in electrophoretic mobility shift assays (EMSAs) (9).

To further elucidate the essential promoter elements of Hes1 and other Notch target genes in the studies reported here, the promoter activity was examined directly through reporter gene assays. Because MAM has been shown to recruit important proteins that are essential for proper transcriptional regulation, these experiments examined the promoter activity in the presence of both NICD and MAM. Mutation analysis was used to determine which promoter elements are necessary for transcriptional activation of Hes1. Individual and combinations of NREs were mutated along with the SPS spacing and orientation. The residue responsible for forming a NICD dimer was also mutated. The Hes1 TATA box was mutated, as well as the TATA box in Hairy/Enhancer of Split 5 (Hes5), another Notch target gene that contains an SPS. The 
number of base pairs between SPS and the TATA box were both increased and decreased in mutant Hes1 promoters.

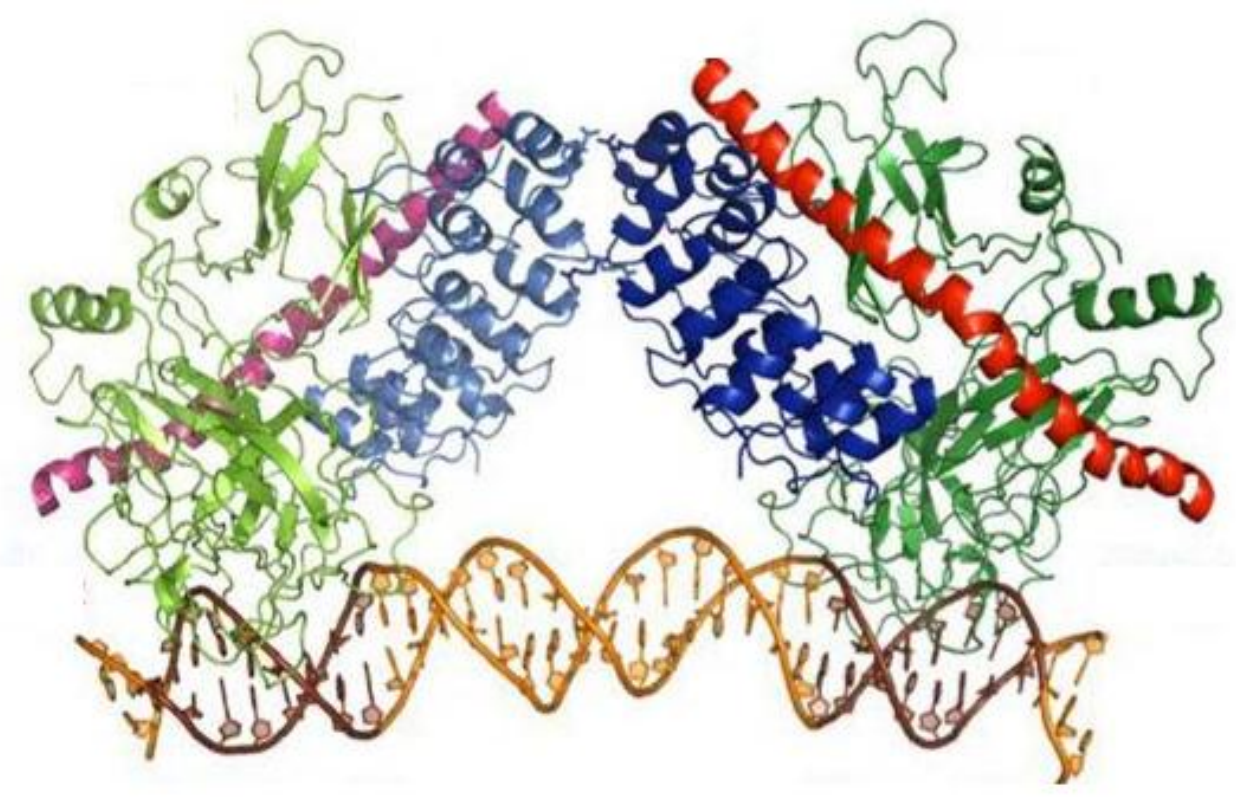

FIGURE 4: Crystal structure of Notch complex dimers assembled on the Hes1 promoter. Dark and light green ribbons represent CBF1 protein bound to NREs 2 and 4. Red and pink ribbons represent the N-terminal helix of MAM. Light and blue ribbons represent ANK domain on NICD. Adapted by permission from Macmillan Publishers Ltd.: Nat. Struct. Mol. Biol. (11), copyright 2010.

These findings demonstrated that the SPS on NREs 2 and 4 on Hes1 are both essential to promoter activity since mutations of individual or both SPS elements abolished activation. NREs 1 and 3 did not appear to contribute to activation. Perturbing the spacing between the SPS elements produced reduced promoter activity, so proper SPS spacing is essential for promoter activation. The NICD mutant data confirmed that the dimer between the activation complexes is essential for promoter activity. Changing the SPS orientation to Tail-Head and Head-Head from the wildtype Head-Tail orientation significantly reduced promoter activity, suggesting that SPS orientations are crucial for 
transcription. The Tail-Tail orientation showed promoter activity at the same level as wildtype. Results also showed that the TATA box is crucial for Hes1 and Hes5 activation, meaning that the TFIID complex or TATA-binding protein (TBP) alone is necessary for transcription. The SPS was effective in activating the promoter when moved up to 150 base pairs upstream from the TATA box, suggesting that Notch activation complexes may stabilize the TFIID complex through other proteins bridging their interaction, or directly through a DNA looping mechanism. Taken together, these results suggest that NICD- and MAM-mediated transcription activation requires a TATA box and a spacing- and orientation-dependent SPS. 


\section{LITERATURE REVIEW}

\section{Overview of Notch Signaling}

Notch was first discovered 100 years ago when a mutation that disrupted the gene produced a notched wing phenotype in Drosophila melanogaster (12). Since then, Notch has been genetically and molecularly characterized in various organisms. Notch signaling regulates important cellular processes, such as differentiation, growth, and death (1). This pathway is named after Notch, a transmembrane protein with an extracellular receptor used to communicate with adjacent cells. Notch signaling is found in all metazoans; the number of Notch receptors, however, varies with the complexity of the organism. For example, while the fruit fly Drosophila melanogaster has only one Notch receptor, mammals have four Notch receptors to accommodate more diversified pathways. The pathway serves important and diverse functions, and aberrancies in Notch signaling often result in disease and dysfunction in many types of tissues. In aberrant Notch signaling, Notch functions as an oncoprotein or tumor suppressor depending on the cellular context (13). Mutated Notch has been linked to cancers, such as T-cell acute lymphoblastic leukemia and mammary tumorigenesis, and neurological disorders, such as CADASIL and Alzheimer's disease (14-17).

Synthesis of the Notch protein is synthesized in the endoplasmic reticulum, where the protein O-fucosyltransferase (OFUT) 1 binds to Notch. The fucosyltransferase activity of OFUT1 is responsible for the proper folding of Notch (18). After Notch is transported to the Golgi body, it is cleaved by a furin-like convertase, resulting in a Notch extracellular subunit (NECD) and a Notch transmembrane subunit (NTM) that are 
tethered together non-covalently at a site called S1 in the heterodimerization (HD) domain $(19,20)$. Notch is transported to the cell membrane, where it functions as a single-pass transmembrane protein that appears at the cell surface (20). The NECD also contains Epidermal Growth Factor (EGF)-like repeats and three conserved Lin12/Notch repeats (LNR). The LNR and HD domains together comprise the negative regulatory region (NRR), which is essential for the prevention of non-specific, ligand-independent proteolytic cleavage that prematurely dissociates the NECD and NTM (21).

Notch communicates with cells through direct contact by binding its NECD to ligands expressed as transmembrane proteins in adjacent cells. This selective cell-cell interaction is believed to mediate spatiotemporal Notch signaling in vertebrate development. Notch ligands are members of the Delta/Serrate/LAG-2 (DSL) family of proteins. Delta and Serrate were the first ligands to be identified as Notch ligands in Drosophila (22). In mammals, Notch ligands include Jagged 1 and 2, homologs of Serrate, and Delta-like 1,3, and 5. The DSL ligands bind to the NECD on its EGF-like repeats. The Golgi body contains Fringe, which can site-specifically glycosylate Notch EGF-like repeats during protein processing; modifications by Fringe appear to adjust Notch responsiveness to different ligands (23). When a ligand binds to Notch, Notch becomes sensitive to cleavage by tumor necrosis factor- $\alpha$ converting enzyme (TACE), a protease from the ADAM (A Disintegrin And Metalloprotease) family, at a site called S2 in the Notch HD domain (24). When the NECD is dissociated from NTM after proteolytic cleavage, this results in an intermediate form of Notch that acts as a substrate for a presenilin-dependent gamma-secretase. This enzyme cleaves NTM inside the cell 
membrane between G1743 and V1744 on a site called S3. Cleavage at S3 releases the Notch intracellular domain (NICD) $(2,25)$.

The NICD contains a Recombination Binding Protein-associated module (RAM) domain and several ANK repeats for interactions with other proteins. The NICD also has a proline, glutamate, serine, and threonine rich (PEST) domain that is necessary for degradation. When released, NICD proteins form multimers within the cell in an antiparallel orientation through its $\mathrm{N}$ - and C-terminal regions. Ski-interacting protein (SKIP) binds to the NICD multimers, forming a docking site for MAM (26). Next, the NICD is then released from SKIP as a monomer bound to MAM (26). This forms the Notch transcription activation ternary complex consisting of CBF1, NICD, and MAM. SKIP has been shown to associate with CBF1 upon activation by NICD, and it is postulated that the NICD RAM domain contains a region that can bind to CBF1 at its four amino acid $\Phi \mathrm{WP}(\Phi=$ hydrophobic residue $)$ motif and also a separate region necessary for multimerization with other NICD proteins $(6,26,27)$. CBF1 may displace SKIP from the RAM domain by steric crowding; therefore, the NICD RAM domain could be responsible for toggling between the pre-activation complex and the ternary activation complex. Because SKIP delivers NICD and MAM to CBF1, SKIP appears to be a limiting factor in Notch transcriptional activation. It has been shown that addition of SKIP significantly increases target gene promoter activation by NICD and MAM in vivo (6).

The four mammalian Notch receptors have the same major domains, but vary slightly in their structure. These differences appear to play a role in differential 
expression, both throughout different types of tissues and within the same tissue. The extracellular portion of Notch contains between 29 and 36 EGF-like repeats, and these help to determine binding to specific ligands (28). Only Notch 1 and 2 contain a transactivation domain (TAD), and it has been postulated that the phosphorylation sites on TAD allows Notch 1 and 2 to selectively modulate signaling activity (29). It has also been postulated that the number of ANK repeats dictates target gene activation (30). With different combinations of ligands, four Notch receptors, and three MAM coactivators, this suggests that the Notch signaling pathway can elicit differential responses depending on cellular context. However, additional data suggests that different MAM proteins dictate activation strength of target genes, regardless of which Notch homolog is used. ${ }^{1}$

$\mathrm{CBF} 1$ is the mammalian version of the $\mathrm{CBF} 1 / \mathrm{Su}(\mathrm{H}) / \mathrm{Lag}-1$ (CSL) protein, which is named for the orthologs in mammals, Drosophila, and C. elegans, respectively. CBF1 is made up of an $\mathrm{N}$-terminal domain, which interacts with the major groove of DNA, a $\beta$ trefoil domain that interacts with DNA minor grooves, and a C-terminal domain that does not bind DNA. CBF1 binds to target genes at the consensus sequence RTGRGAR. This sequence varies in different target genes, but the internal guanines of the consensus sequence are essential for CBF1 binding (4). In the absence of Notch, CBF1 binds to a transcriptional corepressor complex comprising Silencing Mediator of Retinoid and Thyroid hormone receptors (SMRT). The SMRT complex recruits histone deacetylase (HDAC)-1 and SMRT/HDAC-1 Associated Repressor Protein (SHARP), and

${ }^{1}$ T. M. Burke and J. B. White, unpublished data 
CBF1 Interacting Corepressor (CIR) with HDAC-2 (31-33). Interaction of CBF1 with amino acids 640-811 in SMRT is also necessary for correct nuclear translocation of CBF1 (34). It is unclear how the presence of NICD displaces the corepressors, but it has been hypothesized that NICD competes with the corepressor complex for binding to CBF1. CBF1 is responsible for the interaction of the activation complex with target genes and also for mediating the protein interactions within the complex. The CBF1 $\beta$ trefoil domain interacts with a 23-residue segment of the RAM domain in NICD, while the CBF1 C-terminal domain simultaneously interacts with the NICD ANK domain and MAM N-terminal helix. In addition, the CBF1 N-terminal interacts with MAM at its Cterminal helix (35). Notch is essential for the correct conformation of CBF1 in the activation complex. Without the Notch RAM domain, the CBF1 N-terminal loop has a closed configuration that cannot interact with MAM. Furthermore, when Notch RAM binds to the CBF1 $\beta$-trefoil domain, the $\mathrm{CBF} 1 \mathrm{~N}$-terminal changes into an open conformation that is suitable for binding to MAM (36).

MAM, a component of the Notch ternary activation complex, has been identified by its similar functionality to its orthologs: LAG-3 in C. elegans and Mastermind in Drosophila. MAM was discovered to only form a complex with CBF1 in the presence of Notch (37). MAM contains a recognition motif with a 52 residue helix that detects binding sites on both CBF1 and Notch simultaneously; NICD with CBF1 without MAM is not sufficient to activate transcription, nor is MAM alone or MAM with CBF1 sufficient $(5,38,39)$. 
MAM has been shown to bind to p300 and c-AMP response element binding protein (CBP), which is necessary for $\mathrm{p} 300$ - and p300/CBP-associated factor (PCAF)acetylation of nucleosomes at Notch target genes. This histone acetyltransferase activity is necessary for activation at chromatin templates (40). Only p300, not CBP, appears to strongly associate to MAM in the presence of NICD (6). CBP is recruited by c-AMP response element binding protein (CREB) transcription factor on Notch responsive genes, as it has been shown on Hes1 (41). Nuclear MAM also selectively recruits CDK8, which hyperphosphorylates NICD by targeting serines at the PEST domain. This Notch ternary complex interaction with CDK8 has been shown to have an inhibitory effect on Notch signaling $(6,42)$. Hyperphosphorylated NICD is a target for SEL10 (Suppressor/ Enhancer of lin-12 10), which contains seven regions with about 40 repeats of tryptophan and aspartate that bind directly to phosphorylated NICD (43). SEL10 is a component of the S-phase kinase-association protein/Cullin/F-box (SCF) complex that functions as an E3 ubiquitin ligase. When ubiquitin is transferred to the phosphorylated proteins, they subsequently become targets for proteasome-mediated degradation. In protein immunoblots, proteasome inhibitors and dominant negative SEL10 without E3 ubquitin ligase activity stabilized NICD (44). While SEL10 has been previously shown to reduce presenilin activity, SEL10 does not modulate Notch signaling through the presenilindependent gamma-secretase cleavage of the receptor (44).

MAM's role in Notch signaling, therefore, appears to activate expression of target genes by integrating with the Notch ternary activation complex and recruiting chromatin modifiers. Upon activation, MAM appears to immediately inactivate gene expression by 
recruiting CDK8, whose phosphorylation of NICD PEST domain becomes the target of proteasomal degradation. This dual role of MAM reflects an important aspect of Notch signaling, highlighting the significance of proper timing of target gene activation. When this simultaneous on-and-off switch cannot occur, diseased states in humans often results, usually when Notch signaling is overexpressed. The first Notch mutation found in humans was identified in T-cell acute lymphoblastic leukemia (T-ALL) patients who had a t(7;9)(q34;q34.3) translocation (14). The disrupted locus on chromosome 9 contained a mutant Notch1 gene that transcribed truncated forms of Notch1 that resembled NICD. NICD is expressed in T-ALL cells regardless of ligand interaction with the Notch receptor, and constitutively active Notch signaling was shown to transform T-cells. Because degradation of NICD is arranged by MAM and CDK8, overexpressed Notch signaling may be due to disruption of the proteasomal pathway.

\section{Overview of Transcription in Class II Promoters}

A protein-encoding gene is transcribed by RNA polymerase, the enzyme that polymerizes nucleotides to form an RNA molecule. In mammals, there are three types of RNA polymerases that encode different RNA molecules: RNA polymerase I produces ribosomal RNA, RNAPII transcribes messenger RNA (mRNA), small nuclear RNA, and microRNAs, and RNA polymerase III synthesizes transfer RNA and other small RNAs (45). RNA polymerase I, II, and III transcribe Class I, II, and III genes, respectively. Target genes of Notch signaling are Class II genes, which are the most well characterized group of genes. 
On Class II genes, RNAPII binds to a region called a core promoter. Some core promoters contain a TATA box, which typically has the consensus sequence TATAA (46). TBP interacts with the TATA box, causing the bound DNA to bend nearly 90 degrees (10). The TATA sequence becomes distorted and general transcription factors (GTFs) are allowed to bind to the core promoter. TBP along with TBP-associated factors (TAFs) make up one GTF, the TFIID complex. Some other GTFs include TFIIA, which stabilizes the interaction between TFIID and DNA, TFIIB, which recruits RNAPII, and TFIIH, which contains helicase activity that unwinds DNA to create the transcription bubble. Together, the GTFs and RNAPII form the pre-initiation complex (10). In core promoters that do not contain a TATA box, the pre-initiation complex can assemble on other promoter elements, such as the Initiator sequence, which contains the consensus sequence $\mathrm{YYANWYY}(\mathrm{Y}=\mathrm{C}$ or $\mathrm{T} ; \mathrm{W}=\mathrm{A}$ or $\mathrm{T})$, where $\underline{\mathrm{A}}$ is the transcription start site. The pre-initiation complex can also bind to upstream and downstream promoter elements. In addition to a pre-initiation complex, other activators can stimulate transcription initiation. This can occur when gene-specific transcription factors, or activators, bind to the promoter to help stabilize or recruit TFIID to the core promoter. One important coactivator is Mediator. Mediator is not necessary for the function of the basal transcription machinery of the pre-initiation complex, but it increases basal transcription levels. It has been shown in mammalian cells that abolishing Mediator results in a loss of transcription $(47,48)$. Mediator is $1.4 \mathrm{MDa}$ and made up of over 30 subunits in mammals. The coactivator consists of a core complex with a head, middle, and tail module, and a kinase module that is loosely associated with the core complex (49). Due 
to Mediator's large size, it can act as a linker between the pre-initiation complex and other gene-specific transcription factors and coactivators. Some researchers refer to Mediator as a GTF since Mediator can act as an adaptor between transcription activators and the core promoter factors. Mediator has been seen to have direct interactions with TBP, TFIIE, and TFIIH, suggesting that Mediator plays a role in recruiting RNA polymerase and helps stabilize the pre-initiation complex (50-52). Mediator has been seen both as a required activator in housekeeping genes that are constitutively expressed and as a recruited activator in target gene activation. Mediator can also interact synergistically with transcriptional coactivators that are involved in chromatin remodeling, such as p300, a histone acetyltransferase (53). Mediator has also been shown to direct the assembly of the pre-initiation complex by binding p300 to TFIID (54). Nucleosomes are acetylated by p300, causing the DNA to dissociate from the histone and subsequently allowing TFIID to bind.

In addition to Mediator's extensive role as a transcriptional coactivator, Mediator has also been shown to repress transcription when it is associated with the kinase module. The Mediator kinase module is composed of four subunits: Med12, Med 13, CDK8, and CycC. Mammalian CDK8 has been shown to be associated with inactive transcription complexes, and leaves when the transcription is activated (55). Structural studies have shown that CDK8 binds to the core region of Mediator, preventing RNA polymerase binding (56). However, CDK8 has also been shown to positively influence transcription initiation in both mouse in vivo and in vitro studies (57). Mediator has been shown to activate and repress transcription initiation activities; however, the roles of each subunit 
and module in transcription initiation and activator recruitment are still not clearly defined. The Notch activation complex utilizes MAM to recruit CDK8, a component of the Mediator kinase module, but it is still unclear whether or not Notch- and MAMmediated activation is Mediator-dependent.

Class II promoters can also be activated by enhancer elements that recruit proteins that activate transcription. Enhancers are defined as elements that are located upstream or downstream of the core promoter and can activate transcription regardless of their orientation (58). The distance from the core promoter can vary greatly among genes. One enhancer for the Sonic hedgehog gene in developing mouse limb buds has been located over $1 \mathrm{Mb}$ away from the promoter (59). One mode of action used by enhancers is the looping of DNA so that the activator and the GTFs on the core promoter are brought close together. DNA looping was first discovered in the L-arabinose operon in E. coli, and can be determined today using chromosome conformation capture to examine if a distal element is brought closer to the promoter (60). One simple mechanism of enhancers utilizes free diffusion in the nucleus to join the activator and core promoter complex. Activators bound to enhancers can also dynamically scan DNA until interacting with the core promoter complex to initiate transcription (61).

\section{Hes1 Promoter and Sequence-Paired Sites}

One well characterized mammalian target gene of the Notch signaling pathway is Hes1, a paralog of Drosophila Hairy and Enhancer of Split. The HES1 protein in Drosophila inhibits neurogenesis. Additionally, HES1 has been shown to be a 
transcriptional repressor in mouse models as well (62). HES1 is a basic helix-loophelix (bHLH) protein that binds to $\mathrm{N}$ boxes (CACNAG) on its target gene promoters. This is a unique characteristic of HES 1 since most bHLH proteins preferentially bind to promoter E boxes (CANNTG) (63). By directly binding to the DNA, HES1 can recruit additional repressors such as Drosophila Groucho or mammalian Grg (62). HES1 plays crucial roles in neural, muscle, endocrine, exocrine, and T-cell development, as well as other important functional tissues (64). HES1 is necessary for maintenance of undifferentiated cells. HES1-deficient mice show premature differentiation and developmental abnormalities in various tissues, such as brain, eye, and pancreas $(65,66)$. Therefore, HES1 is responsible for maintaining populations of precursor cells until signaled by differentiation cues. Because of its diverse functions, control of Hes1 is tightly regulated in a tissue-specific manner. Regulation of HES1 expression is heightened by its autoregulatory negative feedback loop in which HES1 protein binds to its own promoter at $\mathrm{N}$ boxes to repress transcription (67).

The Hes 1 promoter has over $95 \%$ sequence homology with human and rat Hes1 (68). Structural characterization of the Hes1 showed that the gene is located on chromosome 16 and contains four exons. The first coding region begins 248 base pairs after the transcription start site (TSS). There is a TATA box at 31 base pairs upstream and a CAAT box for CAAT-protein binding at 151 base pairs upstream of the TSS. Hes1 contains four $\mathrm{N}$ boxes at $-165,-132,-58$, and +16 , and HES1 protein binds to the Hes1 promoter at the three $\mathrm{N}$ boxes upstream of the TSS (69). In addition to the $\mathrm{N}$ boxes, Hes1 promoter contains four additional regulatory elements called Notch response 
elements (NREs), where the Notch ternary activation complex binds through CBF1. These NREs are located upstream of the TSS at -107 (NRE 1 on the negative strand), -85 (NRE 2 on the positive strand), -71 (NRE 3 on the positive strand), and -62 (NRE 4 on the negative strand). NREs typically contain the consensus RTGRGAR; although NREs 3 and 4 contain a single base pair that do not match the consensus, all the NREs contain the guanines that are necessary for CBF1 binding (4). The putative CBF1 binding site at NRE 3 has not been addressed in previous literature, and it appears that this site being addressed for the first time in the experimental studies presented here.

The Drosophila promoter Enhancer of Split, or E(spl), is a homolog of Hes1 and a Notch signaling target gene. $\mathrm{E}(\mathrm{spl})$ contains two NREs oriented as a sequence-paired site (SPS), an evolutionarily conserved pattern of inverted repeats of NREs (70). The first NRE of the SPS is located on the positive strand and designated as a Head site, while the second NRE of the SPS is on the negative strand and designated as a Tail site. These NREs are separated by 17 base pairs. Cave et al. examined the importance of the SPS as well as bHLH binding sites in activation of $\mathrm{E}(\mathrm{spl})$ promoter by Drosophila NICD (dNICD) and the proneural bHLH proteins Achaete and Daughterless (Ac/Da) (71). They found that the native promoter is activated synergistically by dNICD and Ac/Da, but not by dNICD or Ac/Da alone. When either of the NRE sites are mutated, the $\mathrm{E}(\mathrm{spl})$ promoter is only weakly activated by $\mathrm{dNICD}$ and Ac/Da alone or together. This study framed a promoter code for Notch target gene activation in which the SPS is necessary for promoter activity, and the Notch complex can work synergistically with other proteins in order to activate transcription. 
Like the synergistic activation of Notch target genes in Drosophila, Notch and MAM work together through Notch ternary complexes in order to stimulate transcription initiation $(6,72)$. On Hes1, the SPS motif appears on NRE 2, a head site, and NRE 4, a tail site, and these are separated by 16 base pairs. Studies have shown that a Notch complex binds to a single NRE site and many groups believe this assembly can activate transcription in mammals $(11,73)$. However, it has been shown that abolishing the SPS on Hes1, either by mutating a single NRE or by changing the orientation of the second NRE, produces a decreased level of promoter activity compared to wildtype when NICD is transfected into cell culture with Hes1 fused to a reporter gene (8). Nam et al. examined the importance of the SPS and reported that the Notch complexes cooperatively dimerize on the Hes1 SPS in order to induce transcription. This group solved a crystal structure containing dimerized Notch ternary complexes on a synthetic promoter derived from Hes1. The dimerization occurred on NREs 2 and 4 through key residues that form salt bridges between the Notch ANK domains. These residues are conserved across a wide range of animals, including Drosophila (9). When the native Hes1 promoter was transfected with a NICD construct containing one mutated ANK residue at amino acid 1985, promoter activity was abolished. Additionally, this study used EMSAs to show that proper dimerization cannot occur when NRE 2, NRE 4, or both are mutated, when NRE 4 is inverted, nor when the spacing between the SPS is increased by four base pairs or decreased by two.

These studies raised questions of whether or not the SPS is important for Notchand MAM-mediated transcription activation of the native Hes1 promoter and other Notch 
target genes. Hes1 has a TATA box which recruits the general transcription factor TFIID, but it is not been determined whether or not TATA boxes contribute to transcription activation on Notch target genes. It has been postulated that Notch- and MAM-mediated activation occurs when MAM recruits CDK8, which may recruit the Mediator complex to assemble the transcription pre-initiation complex (6). While the two NREs on Hes1 comprising an SPS were found to be necessary to activate the promoter, these tests had yet to be performed to assess to synergistic activation by NICD and MAM together. Also, it has not yet been determined whether or not the two unpaired sites on Hes1 contributed to NICD- and MAM-mediated activation. Additionally, new research questions can assess whether Notch and MAM activation of Hes1 is dependent on the orientation of the SPS, the spacing between the SPS, and the spacing between the SPS and the TATA box. Ong et al. showed that increasing the distance between the SPS and the TSS by $1 \mathrm{~kb}$ decreased promoter activation by Notch; however, MAM was not included in these studies, so it was still undetermined whether or not the coactivators recruited by MAM account for activation by the SPS from a distance (8). Additionally, Notch has been shown to regulate position-dependent transcriptional enhancers in Drosophila, and therefore the role of Notch as a activator bound to enhancer sequences can be further studied in mammals (74). 


\section{EXPERIMENTAL PROCEDURES}

\section{Materials and Equipment}

HeLa cells were purchased from the American Type Culture Collection. Cells were grown in Dulbecco's modification of Eagle's medium (DMEM). The DMEM was supplemented with $10 \%$ fetal bovine serum (FBS) axnd 1\% penicillin and streptomycin (denoted as complete medium) and was stored at $37^{\circ} \mathrm{C}$ and $5 \% \mathrm{CO}_{2}$. DMEM with high glucose, L-glutamine, and sodium pyruvate was purchased from Mediatech (Manassas, VA).

Transfection reagent Lipofectamine 2000, Opti-MEM Reduced Serum Medium, Subcloning Efficiency DH5a Competent Cells, and Gateway LR Clonase II Enzyme mix were purchased from Life Technologies (Carlsbad, CA). Custom DNA Oligos for use as mutagenic primers were also purchased from Life Technologies (Table 1). QuikChange II XL Site-Directed Mutagenesis Kit was purchased from Agilent Technologies (Santa Clara, CA). GenCatch Plasmid DNA Maxi Prep Kit was purchased from Epoch Life Science (Missouri City, TX). Buffers P1, P2, P3, QBT, QC, and QF were purchased from QIAGEN (Germantown, MD). Dual Luciferase Reporter Assay System, pRL-TK, and PureYield Plasmid Miniprep System was purchased from Promega (Madison, WI). pGL2-Hes1 was a gift from K.A. Jones (Salk Institute for Biological Studies), and this construct was originally cloned in Reference (7). pGL2-Hes5 was a gift from R. Kageyama (Kyoto University), as was originally cloned in Reference (75). Human Notch 1 intracellular domain and Mastermind-like 1 were cloned in frame to Myc tags in the pCS2-6MT vector, which was originally cloned in Reference (76). 
Luminescence readings were obtained on two machines manufactured by

Promega: the Veritas Microplate Luminometer and the Modulus II Microplate Multimode Reader. Data analysis was performed using Microsoft Excel and IBM SPSS Statistics 20 software.

\section{Generation of Mutant Plasmids by Site-Directed Mutagenesis}

Reagents from the QuikChange II XL Site-Directed Mutagenesis Kit were used for the site-directed mutagenesis reactions. One reaction contained the reagents and thermal cycler parameters listed in Tables 1 and 2.

\section{TABLE 1}

\section{Reaction conditions for site-directed mutagenesis.}

\begin{tabular}{l} 
Volume $(\mu \mathrm{l})$ \\
\begin{tabular}{|l|l|}
\hline 5 & Reagent \\
\hline 0.5 & Tex Reaction Buffer \\
\hline 1 & Forward primer $[150 \mathrm{ng} / \mu \mathrm{l}]$ \\
\hline 1 & Reverse primer $[150 \mathrm{ng} / \mu \mathrm{l}]$ \\
\hline 1 & dNTP mix \\
\hline 3 & QuikSolution \\
\hline 38.5 & water \\
\hline 1 & PfuUltra HF DNA polymerase \\
\hline
\end{tabular} \\
\hline
\end{tabular}

TABLE 2

Thermal cycler conditions for site-directed mutagenesis reactions.

\begin{tabular}{|l|l|l|l|}
\multicolumn{1}{l}{ Segment } & \multicolumn{1}{l}{ Cycles } & \multicolumn{1}{l}{ Temperature $\left({ }^{\circ} \mathrm{C}\right)$} & \multicolumn{1}{l|}{ Time } \\
\hline 1 & 1 & 95 & $1 \mathrm{~min}$ \\
\hline \multirow{3}{*}{2} & \multirow{3}{*}{18} & 95 & $50 \mathrm{~s}$ \\
\cline { 3 - 4 } & & 60 & $50 \mathrm{~s}$ \\
\cline { 3 - 4 } & & 68 & $7 \mathrm{~min}$ \\
\hline 3 & 1 & 68 & $10 \mathrm{~min}$ \\
\hline
\end{tabular}


The cycled reaction was incubated with $1 \mu \mathrm{DpnI}$ at $37^{\circ} \mathrm{C}$ for $2 \mathrm{~h}$ in order to digest template DNA. Next, the digested reaction was transformed into Subcloning Efficiency DH5 $\alpha$ competent cells. A volume of $3 \mu 1$ was pipetted into a microcentrifuge tube containing $25 \mu \mathrm{l}$ thawed cells, then the mixture was incubated on ice for $30 \mathrm{~min}$. The mixture was incubated in a $42^{\circ} \mathrm{C}$ water bath for $20 \mathrm{~s}$, then moved to ice for $2 \mathrm{~min}$.

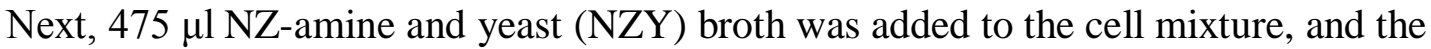
tube was shaken at $37^{\circ} \mathrm{C}$ for $1 \mathrm{~h}$ at $225 \mathrm{rpm}$. On lysogeny broth (LB) and agar plates with $100 \mu \mathrm{g} / \mu \mathrm{l}$ ampicillin, $100 \mu \mathrm{l}$ of the transformation reaction was plated and incubated at $37^{\circ} \mathrm{C}$ for $16 \mathrm{~h}$. A single colony of bacteria was inoculated in $5 \mathrm{ml} \mathrm{LB}$ broth with 100 $\mu \mathrm{g} / \mu \mathrm{l}$ ampicillin and shaken at $37^{\circ} \mathrm{C}$ for $1 \mathrm{~h}$ at $225 \mathrm{rpm}$.

The plasmid was purified from $4.5 \mathrm{ml}$ bacterial culture using PureYield Plasmid Miniprep System. The culture was centrifuged at 5,000 rpm. After discarding the supernatant, the bacterial pellet was resuspended in $600 \mu \mathrm{l}$ Tris-EDTA (TE) buffer. The cell lysate was prepared by adding $100 \mu \mathrm{l}$ Cell Lysis Buffer and $350 \mu 1$ of $4^{\circ} \mathrm{C}$ Neutralization Solution, mixing the solution after the addition of each buffer. The mixture was centrifuged at $13,000 \mathrm{rpm}$ for $3 \mathrm{~min}$, and then the supernatant was transferred to a minicolumn in a collection tube. The collection tube waste was discarded and replaced with the minicolumn. The minicolumn was washed with $200 \mu 1$ Endotoxin Removal Wash and $400 \mu \mathrm{l}$ Column Wash Solution, spinning at 13,000 rpm for $30 \mathrm{~s}$ after addition of each buffer. The minicolumn was removed from the collection tube and placed in a clean $1.5 \mathrm{ml}$ microcentrifuge tube. Next, $50 \mu \mathrm{l}$ TE buffer was added directly to column matrix. After letting column stand for $1 \mathrm{~min}$ at $25^{\circ} \mathrm{C}$, the microcentrifuge tube 
was centrifuged at $13,000 \mathrm{rpm}$ for $30 \mathrm{~s}$. The eluted plasmid was submitted to Sequetech DNA sequencing service (Mountain View, CA) to verify that the plasmid had the correct mutation.

The columns from the GenCatch Plasmid DNA Maxi Prep Kit with QIAGEN buffers were used to obtain transfection quality plasmids. The remaining $500 \mu \mathrm{l}$ bacterial culture was inoculated in $200 \mathrm{ml} \mathrm{LB}$ medium and $100 \mathrm{ng} / \mu \mathrm{l}$ ampicillin. This culture was shaken for $16 \mathrm{~h}$ at $225 \mathrm{rpm}$. After incubation, the culture was centrifuged at 5,000 rpm for $10 \mathrm{~min}$ and the supernatant was discarded. The bacterial pellet was resuspended in 10 ml Buffer P1, Buffer P2, and Buffer P3, with mixing by inverting after addition of each buffer. The column was washed with $30 \mathrm{ml}$ Buffer QBT. The bacteria and buffer mixture was centrifuged at $15,000 \mathrm{rpm}$ for $15 \mathrm{~min}$ at $4^{\circ} \mathrm{C}$, and the supernatant was poured into the maxiprep column. The column was washed with $30 \mathrm{ml}$ of Buffer QC and then eluted with $15 \mathrm{ml}$ of Buffer QF. The eluted plasmid was mixed with $10.5 \mathrm{ml}$ isopropanol and centrifuged at $15,000 \mathrm{rpm}$ for $30 \mathrm{~min}$ at $4{ }^{\circ} \mathrm{C}$. The supernatant was discarded and the remaining DNA pellet was mixed with $5 \mathrm{ml}$ 70\% ethanol and centrifuged at 15,000 rpm for 10 min at $4^{\circ} \mathrm{C}$. The supernatant was discarded and the DNA was allowed to dry. The purified plasmid DNA was resuspended in TE buffer.

\section{Transfection into HeLa Cells}

HeLa cells were plated in complete medium $24 \mathrm{~h}$ prior to transfection in a $96-$ well plate at $2.5 \times 10^{4}$ cells per well. On day of transfection, the complete medium was replaced with $50 \mu \mathrm{l}$ Opti-MEM. Expression constructs (Table 4) for one well were 
diluted in $25 \mu$ Opti-MEM in the following amounts: 100 ng promoter DNA fused to Firefly luciferase, $10 \mathrm{ng}$ NICD, 100 ng MAM, and $10 \mathrm{ng}$ pRL-TK to express Renilla luciferase. pCS2-6MT was added DNA mixture to bring the total DNA amount to 200 ng. Transfection reagent for one well was diluted by adding $0.5 \mu 1$ Lipofectamine 2000 in $25 \mu \mathrm{l}$ of Opti-MEM and incubating for $5 \mathrm{~min}$. The Lipofectamine mixture was then mixed with the DNA dilution and incubated for $20 \mathrm{~min}$. The Lipofectamine and DNA mixture was transferred to one well of HeLa cells. Transfections were performed as technical triplicates.

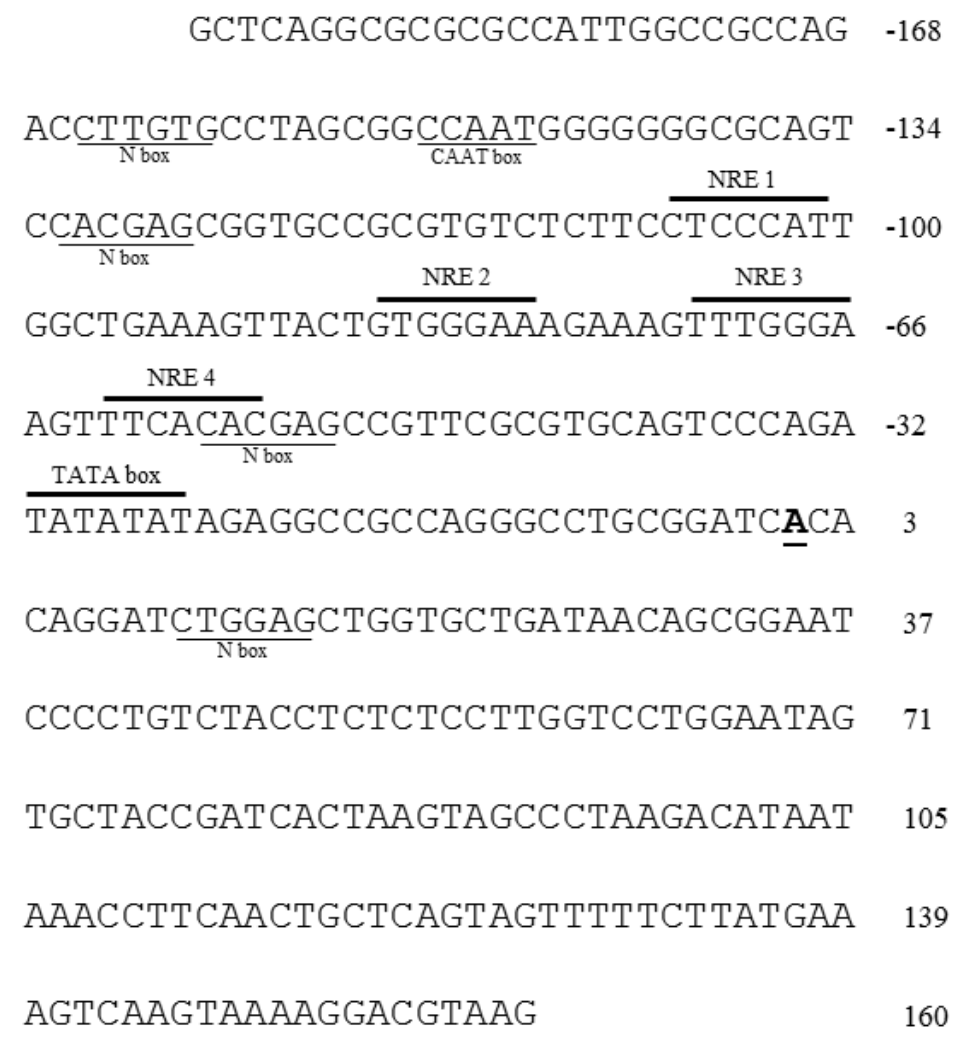

FIGURE 5: Hes1 promoter fragment used in reporter gene studies. This construct was originally cloned into the pGL2-Basic vector with KpnI and BglII in Reference (7). The TSS is denoted as $\underline{\mathbf{A}}$. 


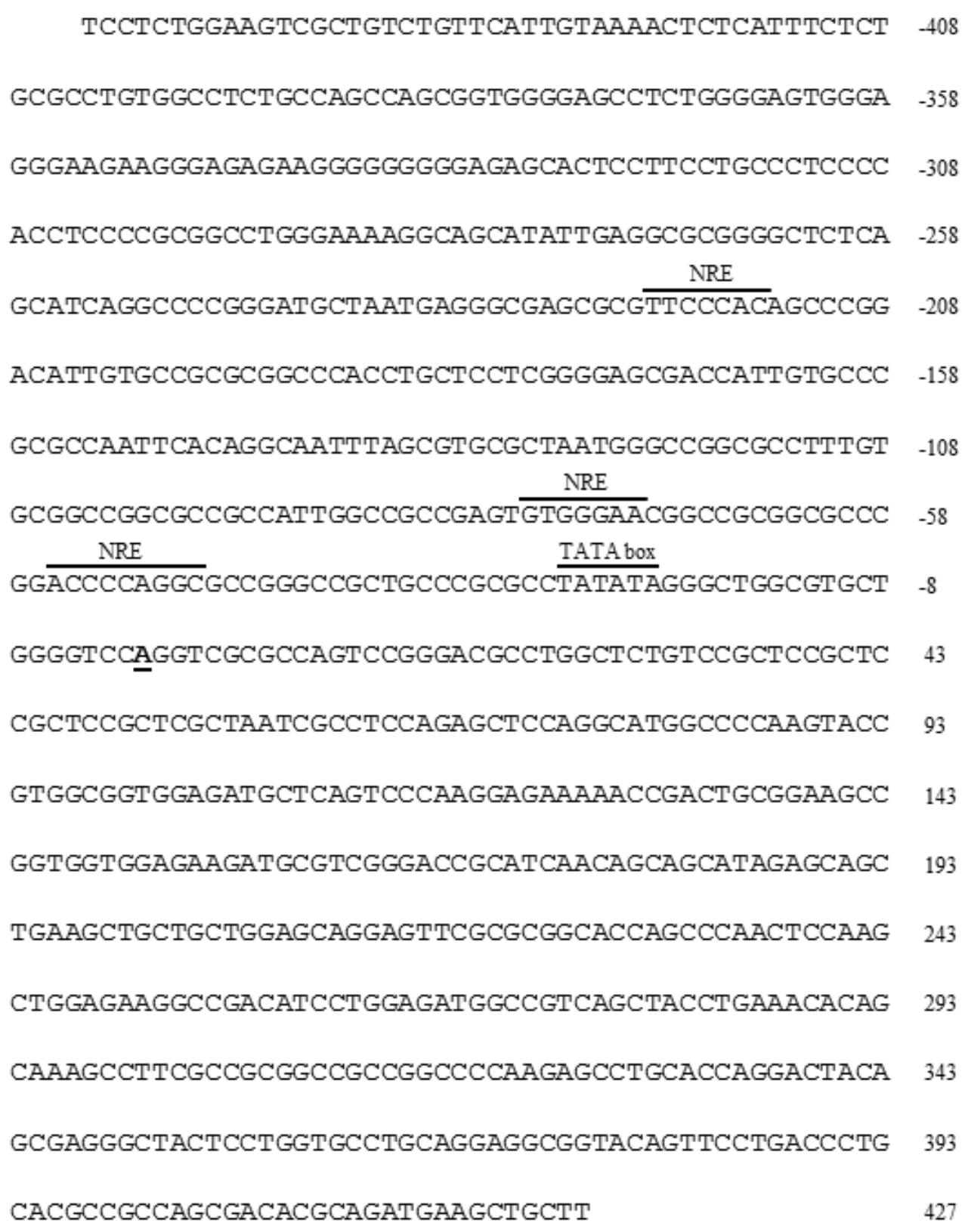

FIGURE 6: Hes5 promoter fragment used in reporter gene studies. This construct was originally cloned into the pGL2-Basic vector in Reference (77). The TSS is denoted as $\underline{\mathrm{A}}$. 


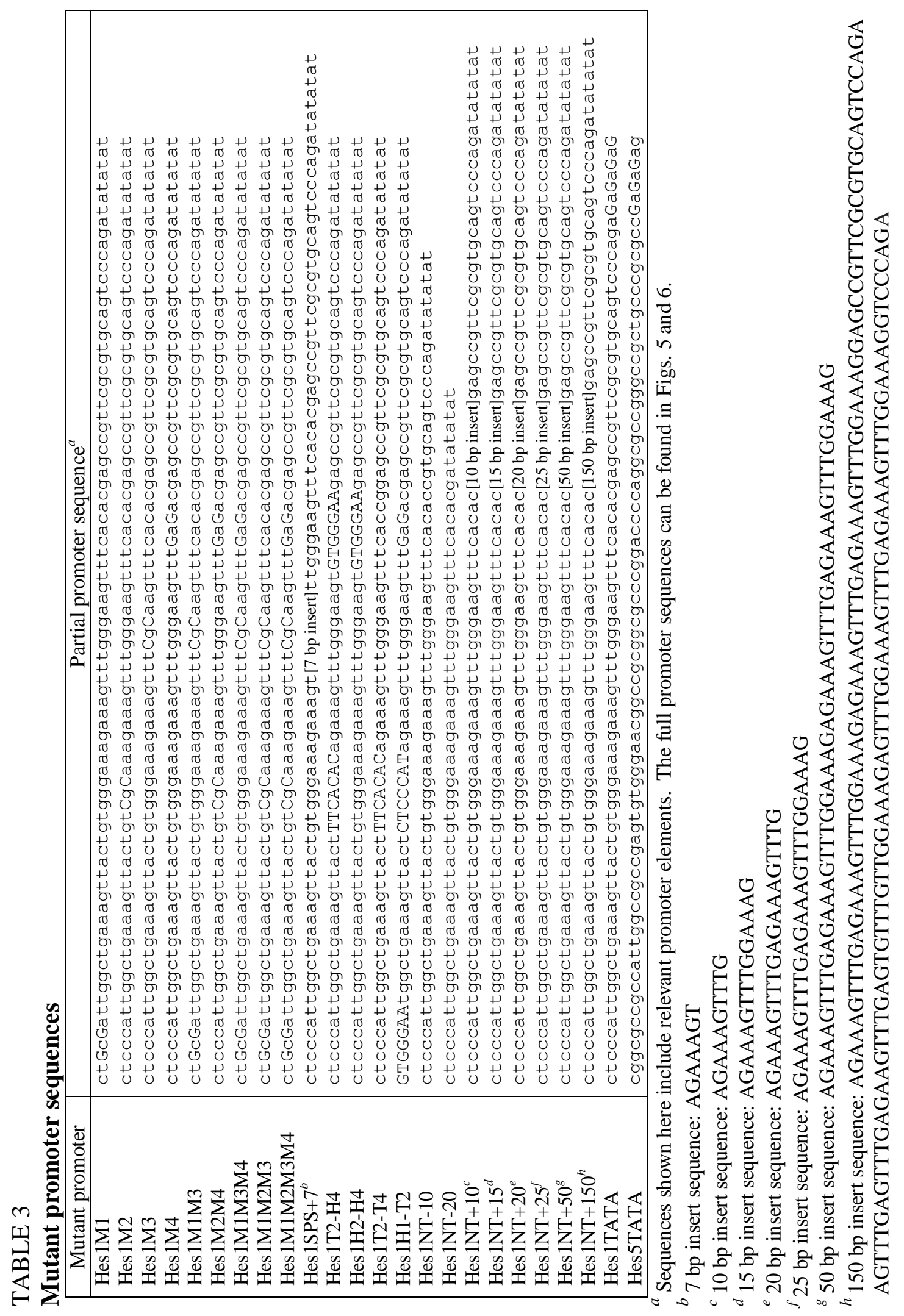




\section{Reporter Gene Assays}

The reporter gene assay was performed $48 \mathrm{~h}$ after the transfection reaction using reagents from the Promega Dual Luciferase Reporter Assay System. The Opti-MEM was aspirated from the well and replaced with $30 \mu 1 \mathrm{XX}$ Passive Lysis Buffer, which is incubated with the cells at room temperature with light shaking for $15 \mathrm{~min}$. After the cells were lysed, $20 \mu \mathrm{l}$ cell extract was transferred to an opaque plate and read on the luminometer. The luminescence readings were measured under the following conditions: $50 \mu 1$ Luciferase Assay Reagent II, $50 \mu 1$ Stop \& Glo Reagent, 5 s delay between injection and measurement, $10 \mathrm{~s}$ integration time. The readings were obtained in Microsoft Excel software. The measurement readings were given as relative light units, and analyzed as a ratio of the Firefly luciferase measurements to the control Renilla luciferase measurements.

\section{Statistical Analysis}

For comparison between activation levels of the wildtype promoter and one other mutant promoter, the data were analyzed using two-tailed independent samples t-tests, and a $p$ value less than 0.05 indicated a statistically significant result. When comparing activation levels of the wildtype promoter and two or more mutant promoters, pairwise independent samples t-tests were performed with the wildtype data. A statistically significant result was indicated by a $p$ value less than a Bonferroni-adjusted $\alpha$, where $\alpha=0.05 / \mathrm{k}$ and $\mathrm{k}=$ total number of promoters compared in the dataset. 
In the studies reported here, the null hypothesis $\left(\mathrm{H}_{0}\right)$ stated that the activation of the mutant promoter and Notch mutants are not different from the wildtype expression constructs. The minimum acceptable risk for a Type I false positive error, where $\mathrm{H}_{0}$ is true but is incorrectly rejected, is $5 \%$ for experimental studies, therefore $\alpha$ was set to 0.05 . When analyzing the mean values of two samples, a $p$ value less that $\alpha$ indicates that the $\mathrm{H}_{0}$ was rejected and the values from one sample set were significantly different from the values of the set to which it was being compared. A $p$ less than $\alpha$ is indicated by an asterisk $(*)$ on the reported figures. Many of the datasets included more than two samples, such as the NRE site mutants which have several samples from the different mutant NRE sites. When multiple samples are compared to wildtype, the risk of a Type I error was increased. In order to combat the problem of multiple comparisons, a Bonferroni correction was applied to $\alpha$ values to restrict the conditions in which $\mathrm{H}_{0}$ was rejected. The smaller $\alpha$ value, which is indirectly proportional to the number of samples, accounted for the $\mathrm{H}_{0}$ that none of the samples is significantly different from wildtype (78). It has been debated that using Bonferroni corrections is a very conservative method for multiple comparisons (79). However, this methodology places much importance on the promoter elements that are found to be statistically significant and assists in powerfully supporting the conclusions presented here. 


\section{RESULTS}

\section{Activation of Hes1 with Notch 1 and Mastermind-like 1}

A luciferase reporter construct containing the wildtype Hes1 promoter was transfected into HeLa cells with either coactivator expression plasmid Notch1 intracellular domain (N1ICD), Mastermind-like 1 (MAM1), or both. The promoter activity of Hes1 alone was normalized to 1; the activity of Hes1 with N1ICD and MAM1 are shown as fold promoter activities compared to Hes1 alone (Fig. 7). These results are consistent with other research groups that have shown that NICD and MAM work synergistically to activate Hes1 transcription, but show very weak activation individually $(6,72)$.

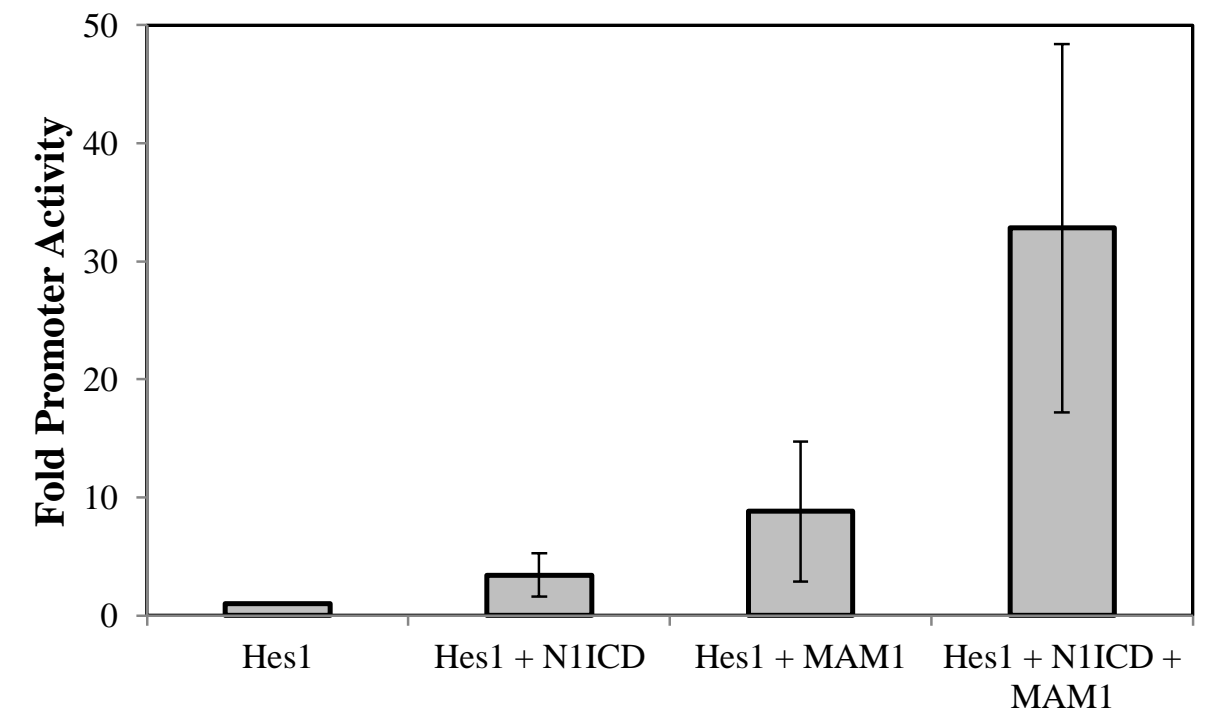

FIGURE 7: Fold promoter activities of Hes1 with N1ICD and MAM1. Fold promoter activities of are normalized to Hes1 promoter alone. Data are shown from at least three independent experiments. Standard deviation bars are shown. 


\section{Notch 1- and Mastermind-like-1-Mediated Hes1 Activation with Mutated Notch Response Elements}

The NREs on Hes1 were mutated by changing the internal guanines to cytosines so that CBF1 could no longer bind. N1ICD and MAM1 were transfected with Hes1 promoter and Hes1 promoters with mutant NRE sites (Fig. 8). N1ICD- and MAM1mediated activations of Hes1M1, Hes1M3, and Hes1M1M3 were not significantly different from Hes1, demonstrating that NREs 1 and 3 do not contribute to activation on the Hes1 promoter. Activations of Hes1M2, Hes1M4, and Hes1M2M4 were significantly decreased compared to wildtype, showing that NRE 2 and NRE 4 are necessary for Hes 1.

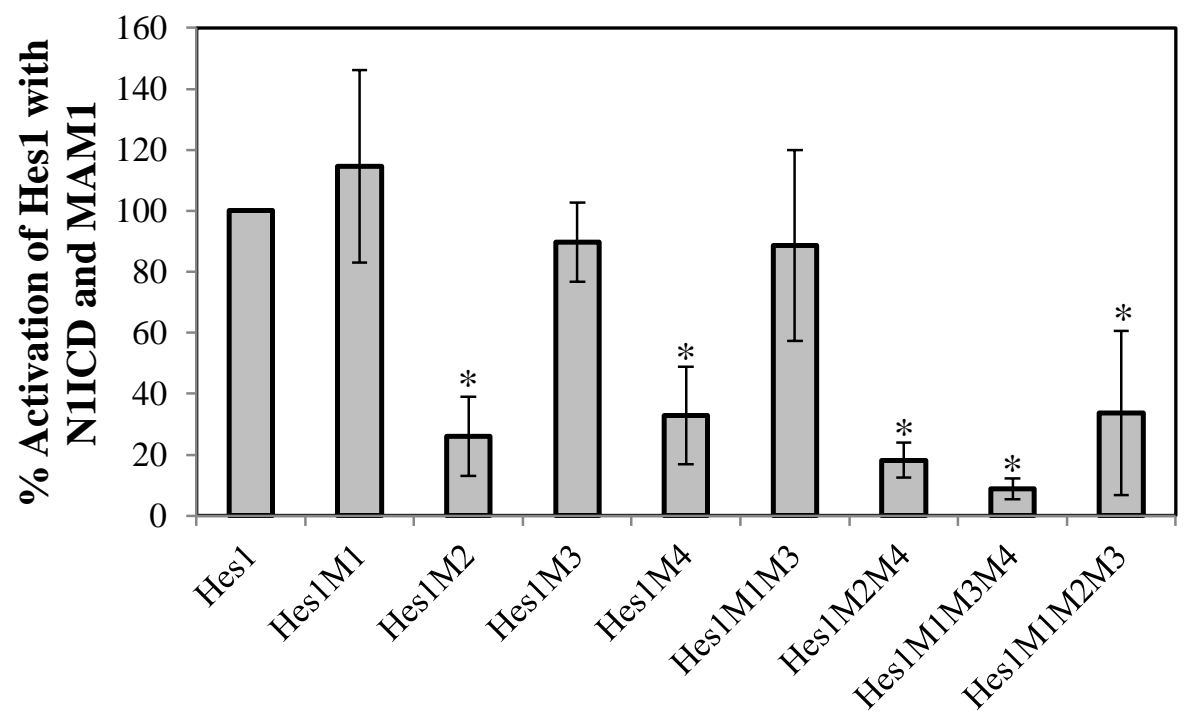

FIGURE 8: Activation of Hes1 NRE site mutants. The Hes1 promoter activation by MAM1 and N1ICD is normalized to $100 \%$ and the activity of the mutant promoters with MAM1 and N1ICD is shown as a percentage compared to wildtype. Data are shown from at least three independent experiments. Standard deviation bars are shown. * denotes $p<0.0055$.

NRE 2 and 4 together comprise the SPS motif that was proposed by Cave et al. to be important for Notch target gene activation (71). Activation by N1ICD and MAM1 
produced significantly decreased promoter activity of Hes1M1M3M4 and

Hes1M1M2M3. NRE 2 and NRE 4 separately are not sufficient to activate Hes1.

\section{Hes1 Promoter Activity with a Notch Dimerization Mutant}

Site-directed mutagenesis was used to create a mutation in N1ICD by changing the arginine on residue to 1985 to an alanine. Nam et al. proposed that this residue was necessary for the Notch complexes to dimerize on the SPS (9).

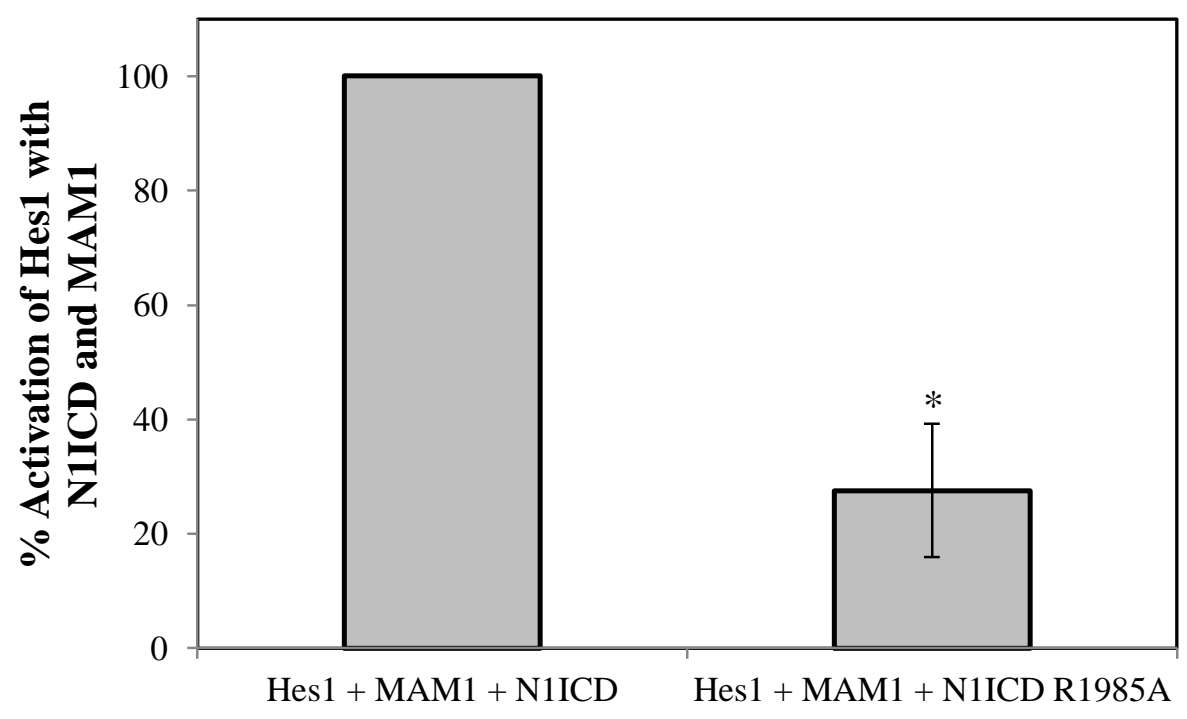

FIGURE 9: Activation of Hes1 with N1ICD R1985A. The Hes1 promoter activation by MAM1 and N1ICD is normalized to $100 \%$, and the activity of Hes1 with MAM1 and the mutant N1ICD is shown as a percentage compared to wildtype. Data are shown from at least three independent experiments. Standard deviation bars are shown. * denotes $p<0.05$

Hes1 activation by MAM1 and N1ICD R1985A was significantly less than activation with the wildtype expression constructs (Fig. 9). This result is in agreement 
with Nam et al. and confirms that the dimerization of the Notch complexes assembled on the SPS is important for Hes1 activation.

Notch- and Mastermind-like-Mediated Activation of Hes1 with a Sequence-Paired Site Separated by Additional Base Pairs

The Hes1SPS+7 promoter construct contained a seven base pair insertion on the 5' end of NRE 4, separating NREs comprising the SPS. According to Nam et al., separating the SPS by an additional seven base pairs eliminates the ability of the Notch complexes to dimerize (9).

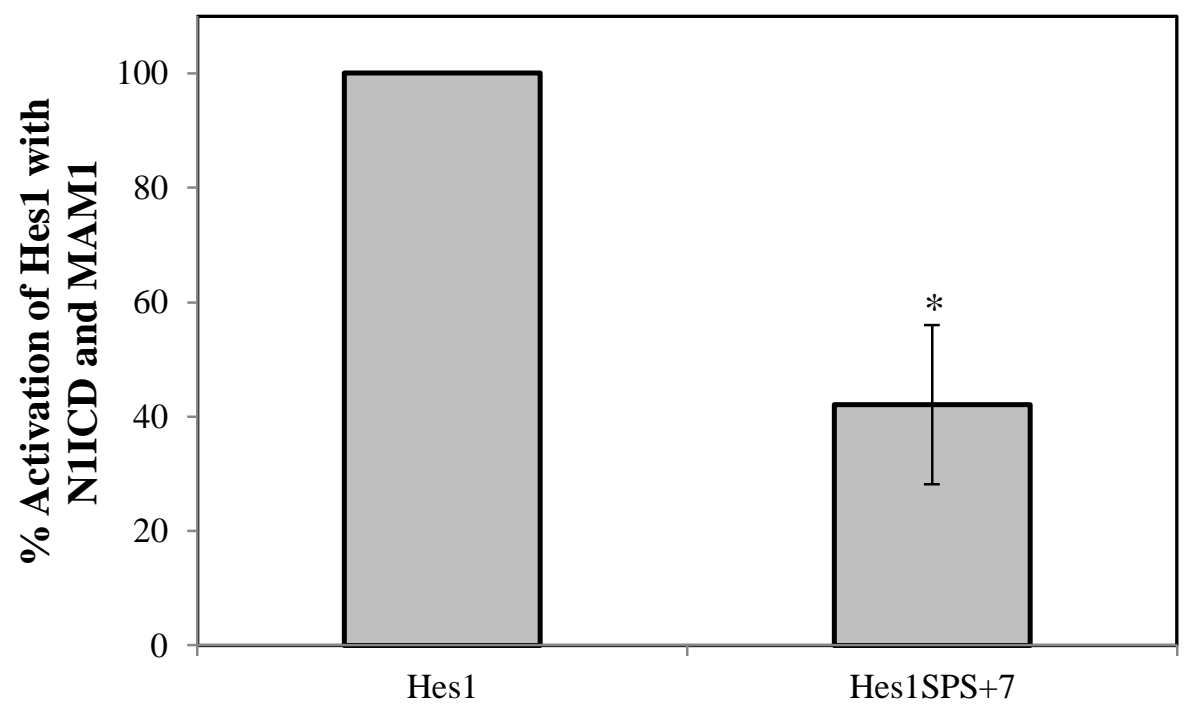

FIGURE 10: Activation of Hes1 with separated SPS elements. The wildtype Hes1 promoter activity is normalized to $100 \%$, and the Hes $1 \mathrm{SPS}+7$ promoter activity is shown as a percentage compared to wildtype. Data are shown from at least three independent experiments. Standard deviation bars are shown. * denotes $p<0.05$

When the Hes1 SPS is separated by 23 base pairs instead of 16 base pairs as it is in the native promoter, promoter activation was significantly decreased (Fig. 10). This 
result strengthens the hypothesis that the dimer assembled on the SPS of Hes1 is necessary for maximum promoter activation by NICD and MAM.

\section{Notch- and Mastermind-like-Mediated Activation of Hes1 with Different Orientations of the Sequence-Paired Site}

To examine whether or not the orientation of the NREs within the SPS are important for Hes1 activation, site-directed mutagenesis was used to change the orientation of NRE 2, NRE 4, or both. The NREs in the wildtype Hes1 SPS are located 16 base pairs apart and are arranged as Head-Tail. When the SPS was arranged as TailHead in Hes1 T2-H4 or Head-Head in Hes1 H2-H4, the promoter activity was significantly decreased compared to Hes1. However, when the NREs were positioned as Tail-Tail in Hes1 T2-T4, promoter activity was not significantly different from wildtype (Fig. 11A).

NRE 1 and NRE 2 on Hes1 are located 15 base pairs apart. Although this differs from the SPS on the native Hes1 promoter that is separated by 16 base pairs, results from Nam et al. have shown that Notch dimers still form when there is a one base pair reduction between the SPS (9). NREs 1 and 2 are arranged as Tail-Head. In the Hes1 H1-T2 mutant promoter, NREs 1 and 2 were mutated so their orientation is Head Tail, and NRE 4 was mutated so that CBF1 cannot bind. Hes1 H1-T2 promoter activity did not differ significantly from wildtype Hes1 (Fig. 11B).

Taken together, these results suggest that the Head-Tail wildtype orientation or the Tail-Tail orientation is necessary for Hes1 activation. 

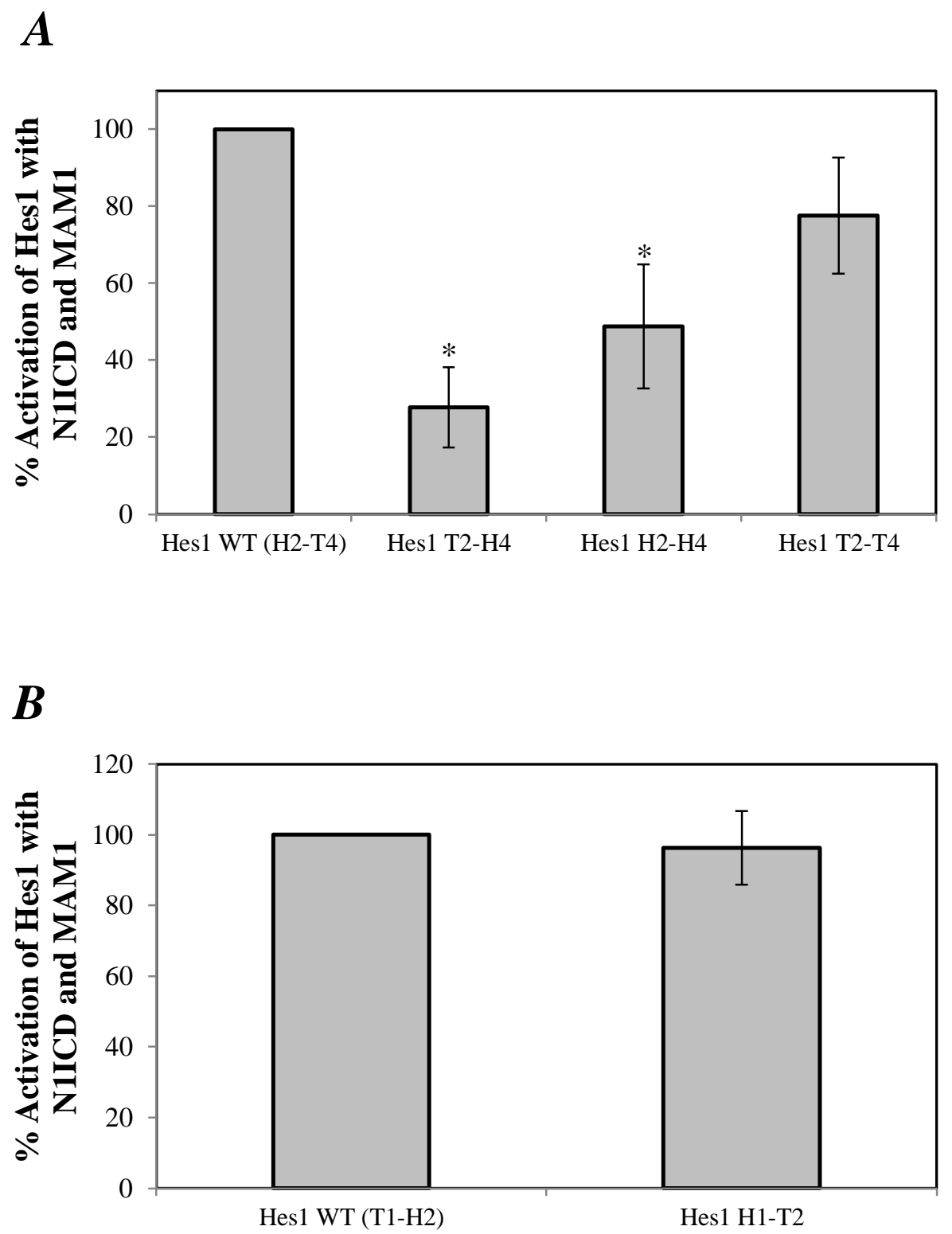

FIGURE 11: Activation of Hes1 SPS orientation mutants. The wildtype Hes1 promoter activity is normalized to $100 \%$, and the mutant promoter activities are shown as a percentage compared to wildtype. A, Activation is shown for mutant promoters where the NREs of the SPS were mutated to show different orientation combinations. $B$, Activation is shown for a mutant promoter in which NRE 1 and NRE 2 were mutated to a Head-Tail orientation to match the wildtype SPS orientation. Data are shown from at least three independent experiments. Standard deviation bars are shown. * denotes $p<0.01$. 


\section{Notch- and Mastermind-like-Mediated Activation of Target Genes with a Mutated TATA Box}

Hes1 contains a TATA box, which recruits RNA polymerase through the TFIID complex. In order to study the contribution of the TATA box to Hes1 activation, sitedirected mutagenesis was used to mutate the TATA box sequence of TATATAT to GAGAGAG. Changing the TATA box thymines to guanines has been previously shown to abolish the functionality of the promoter element (81).

The Hes1 TATA-less promoter, Hes1TATA, had a significantly lower activation by N1ICD and MAM1 than Hes1 (Fig. 12A). This suggests that the pre-initiation complex assembles at the TATA box during transcription initiation. This also indicates that the activation complexes assembled at the NREs alone are not sufficient to activate transcription.

To assess whether or not a TATA box is necessary for other Notch target genes, the TATA box on Hes5 was examined. Hes5 is a Notch target gene that has a TATA box as well as an SPS (11). Hes5TATA is a mutant promoter in which the thymines of the TATA box are mutated to guanines. Activation of Hes5TATA was significantly lower than Hes5 (Fig. 12B).

Taken together, these results suggest that a TATA box is a necessary promoter element on Notch target genes that contain an SPS. 


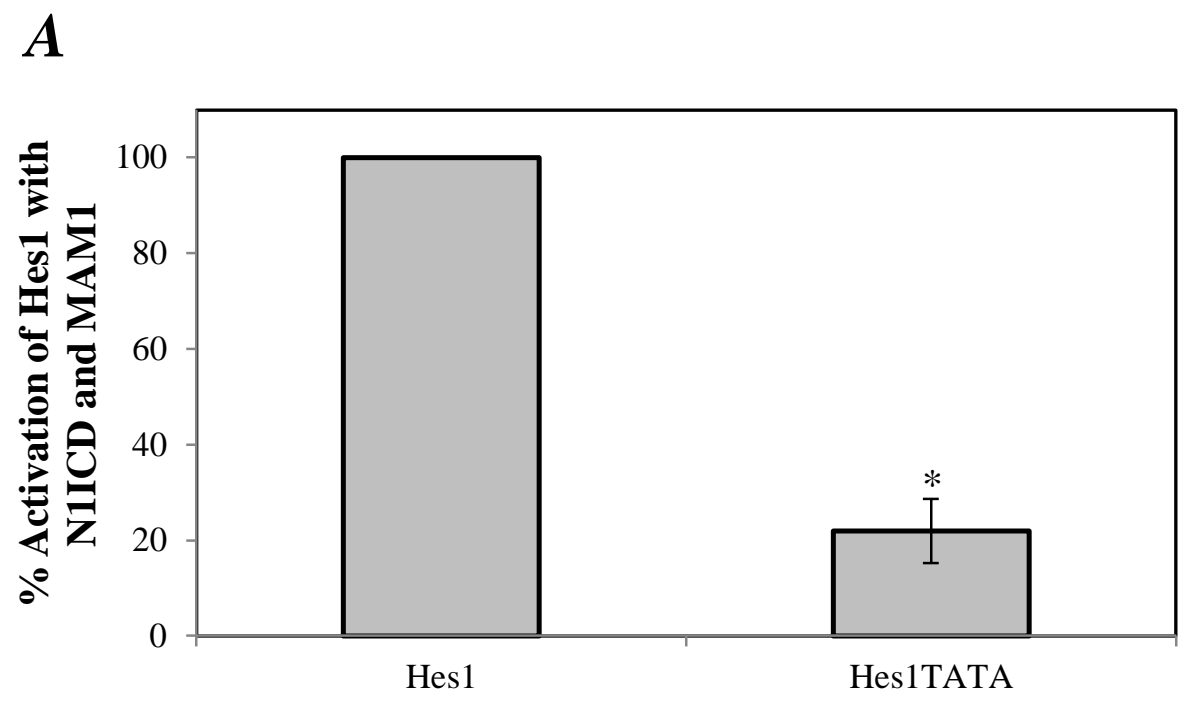

$\boldsymbol{B}$

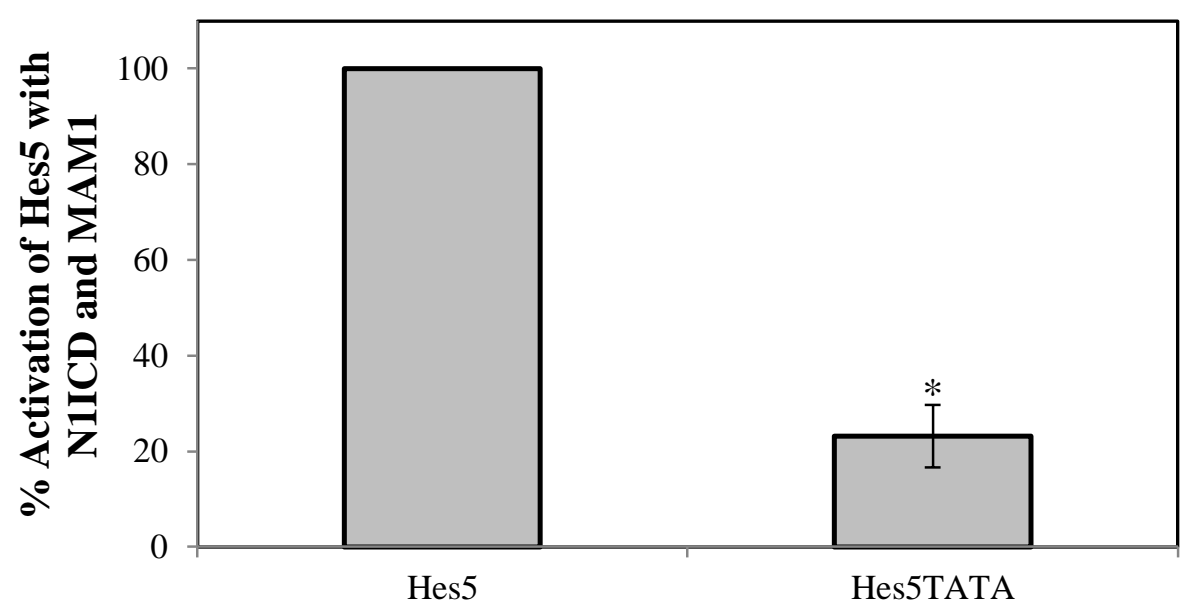

FIGURE 52: Activation of Notch target genes with a mutant TATA box. The wildtype Hes1 promoter activity is normalized to $100 \%$, and the TATA-less promoter activities are shown as a percentage compared to wildtype. A, TATA-less Hes1 promoter activity activation was compared to wildtype activation. $B$, Hes5 TATA box was mutated to assess promoter activity. Data are shown from at least three independent experiments. Standard deviation bars are shown. * denotes $p<0.05$. 


\section{Notch- and Mastermind-like-Mediated Activation of Hes1 with Altered Base Pair Spacing between the Sequence-Paired Site and TATA Box}

Since the Hes1 SPS and TATA box have been shown to contribute to promoter activation, altering the number of base pairs between these promoter elements can offer insight into the nature of the interactions between the Notch activation complexes and the

pre-initiation complex. The 24 base pairs between the NREs and TATA box on Hes 1 are designated as the NT region.

Hes1NT-10 and Hes1NT-20 mutants contained the Hes1 promoter with 10 and 20 base pairs, respectively, removed from the NT region. When activated by N1ICD and MAM1, both Hes1NT-10 and Hes1NT-20 had significantly reduced promoter activity compared to Hes1 (Fig. 13A). This suggests bringing the Notch activation complex closer to the protein complex bound to the TATA box on the Hes1 is detrimental for promoter activity.

Hes1NT+10, Hes1NT+15, Hes1NT+20, Hes1NT+25, Hes1NT+50, and Hes1NT+150 contained the Hes 1 promoter with 10, 15, 20, 25, 50, and 150 base pairs, respectively, added to the NT region. All of these Hes1 promoters with an increased NT region did not have significantly different promoter activations from wildtype Hes1 (Fig. 13B). This suggests that the Notch activators on SPS can interact with the TFIID complex on the TATA box when the SPS is moved further upstream on the promoter. 

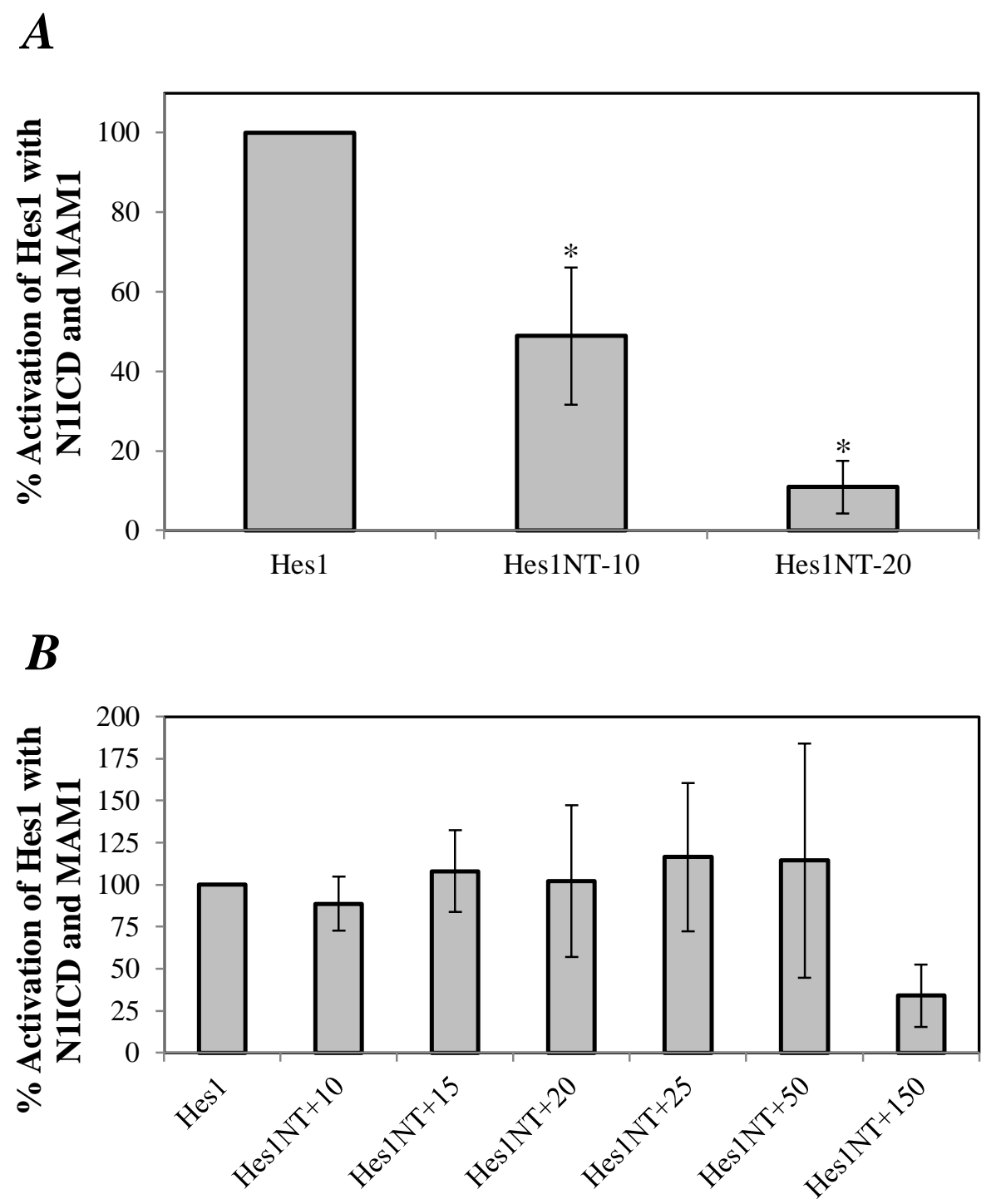

FIGURE 13: Activation of Hes1 with modified spacing between SPS and TATA box. The wildtype Hes1 promoter activity is normalized to $100 \%$, and the mutant promoter activities are shown as a percentage compared to wildtype. A, Activation is shown from mutant promoters where the Hes1 NT region had 10 and 20 base pairs removed. $B$, Activation is shown when up to 150 base pairs were added to the Hes1 NT region. Data are shown from at least three independent experiments. Standard deviation bars are shown. * denotes $p<0.0055$. 


\section{DISCUSSION}

Uncovering the mechanism of MAM-dependent Notch target gene activation is crucial for understanding Notch signaling gene regulation. This is important from a scientific discovery perspective because little is known about Notch signaling, including how target genes are activated, which functional domains contribute to activation, and how combinations of ligands and Notch homologs selectively modulate gene expression. Studying Notch has beneficial consequences for clinical research as well since Notch signaling influences cell immunity, tumor angiogenesis, and stem cell maintenance (81).

Transcriptional coactivators of Notch have been identified, but the mechanisms of transcription machinery assembly and initiation still need further clarification. Studying promoter elements of Notch target genes and their effect on activation provides insight into transcription initiation mechanisms. The results presented here show that two of the NREs on the Hes1 promoter are necessary for Notch- and MAM-mediated activation. NRE 2 and NRE 4 comprise the SPS and appear to contribute to wildtype levels of Hes1 promoter activity; however, neither NRE 2 nor NRE 4 alone is sufficient for activation. NRE 1 and NRE 3 do not appear to play any role in transcription. The lack of activation influence by NREs 1 and 3 is surprising given that these sequences contain the necessary components for CBF1 binding (4). Future studies can discern if these NREs do not contribute to activation because of their incorrect arrangement on the promoter or because there are other activators bound to the promoter that block CBF1 binding.

In order to activate Hes1, the Notch complexes on the SPS must be dimerized through the NICD proteins. This is shown by the N1ICD R1985A mutation on the ANK 
domain presented here. This is an agreement with reporter gene results from Nam et al. (9). Unlike Nam et al., the assay results of Hes1 with the N1ICD mutant shown here include MAM. The formation of the NICD dimer regardless of the presence of MAM signifies that the dimerization of the Notch complexes does not depend on MAM. Nam et al. also showed that a Notch complex dimer did not form when the SPS elements were spaced more than four base pairs apart. The results shown here provide the promoter activity of the Hes1 promoter where seven base pairs are inserted between the SPS. Along with previous results, these findings show that the Notch complex dimers bound to the SPS is necessary to activate the Hes1 promoter at wildtype levels.

In addition to the dimer, the orientation of the SPS plays a role in Hes1 promoter activity. The wildtype SPS orientation is Head-Tail. When site-directed mutagenesis was used to manipulate the promoter to form an SPS orientation of Tail-Head and HeadHead, Hes1 activation by N1ICD and MAM1 was significantly reduced. Interestingly, the Tail-Tail SPS orientation promoter activity is not statistically significant from the wildtype orientation. This is a more complete analysis of SPS orientation to supplement studies by Nam et al., which used EMSAs to show that the Head-Head orientation did not form a Notch dimer on Hes1, as well as studies by Ong et al. that utilized reporter gene assays to show that the SPS in a Head-Head orientation gives a reduced activation of Hes1 $(8,9)$. Further studies are required to determine if a dimer is formed during activation of the Tail-Tail SPS.

The importance of SPS for transcription initiation was shown when a simulated SPS was created on NREs 1 and 2. On the wildtype promoter, the orientations of NREs 1 
and 2 are Tail and Head, respectively. At 15 base pairs apart, NREs 1 and 2 meet the spacing requirements for the SPS (9). When they were changed to Head-Tail using sitedirected mutagenesis techniques, the promoter activation was the same level as the wildtype promoter. The Hes1 SPS, a strict layout for orientation, spacing of response elements, and activator interaction, is a required element for Notch- and MAM-mediated transcription initiation. This work opens the possibility that the SPS promoter motif occurs in Notch responsive genes. Future research can utilize the SPS promoter architecture to discover novel direct target genes of the Notch signaling pathway.

In addition to the SPS on which the Notch activation complexes assemble, Hes1 promoter activity also depends on a TATA box. Eliminating the ability of TFIID to bind to Hes1 produces about $20 \%$ promoter activation by N1ICD and MAM1 compared to wildtype Hes1. The importance of the TATA box was also assessed in Hes5, a Notch target gene that contains both an SPS and TATA box. The Hes5TATA mutant also produced about $20 \%$ promoter activation compared to wildtype. This indicates that TFIID, the GTF bound directly to the TATA box, assembles the pre-initiation complex and recruits RNAPII.

Hes1 promoter activity is also regulated by the distance between the SPS and the TATA box. When spacing was reduced, fold promoter activity was proportionally decreased. This suggests that the Notch complexes and TFIID complex encountered steric crowding and therefore competed for binding sites on the promoter. When the spacing between the SPS and TATA was increased up to 150 base pairs, there was not a significant difference in activation compared to the wildtype promoter. This indicates 
that the interaction between the Notch complexes and the pre-initiation complex may not depend on a fixed promoter distance. Since mechanisms such as DNA looping and promoter tracking are utilized by enhancer regions that are located upstream of the core promoter, these results suggest that the SPS is an enhancer element on the Hes1 promoter (61). However, previous studies have shown that the TATA box must remain at a fixed distance from other promoter elements in order to cooperatively initiate transcription. For example, activation of the Pal promoter of Oryza sativa depends on both a TATA box and Initiator element, and when six base pairs were inserted or deleted between the TATA box and Initiator sequence, TATA-dependent activation was abolished (82). Proper spacing of the TATA box has also been shown to be important for selective recognition by other promoter elements. Studies of the adenovirus major late promoter show that transcription does not begin on the preferred transcription start site when the TATA box is not located 21 to 25 base pairs from the Initiator sequence (83). Further investigation of the spacing between SPS and TATA box and the role of SPS as an enhancer can provide insight into additional regulatory mechanisms of Notch signaling.

The results proposed here provide evidence for a new model of Notch activation that may include the CDK8 module interacting with the core Mediator complex, which stabilizes TFIID at the TATA box (Fig. 14A). However, CDK8 only loosely associates with the core Mediator complex and may not recruit Mediator during Notch signaling. Instead of CDK8 bridging the connection between the Notch complexes and the preinitiation complex, the interaction might occur through another protein, such as $\mathrm{p} 300$. 
The histone acetyltransferase, p300, is recruited by MAM and in vivo and in silico research has shown that p300 interacts with many transcriptional coactivators, particularly with proteins associated with open chromatin (84-86). Another model of Notch- and MAM-mediated activation can include a transcription machinery assembly that does not depend on transcription factor stabilization by direct protein interactions, but instead depends on the chromatin remodeling activity of the Notch activation complexes (Fig. 14B).

It has not gone unnoticed that abolishing the SPS or TATA box on Hes1 decreases activation by NICD and MAM only by $80 \%$ and not a complete $100 \%$. Further, although SPS manipulations, such as rearranging the orientation, produce statistically significantly less promoter activity than wildtype, the activation is decreased by only $40-50 \%$. This launches new research questions about whether or not a single, unpaired Notch activation complex can substantially contribute to target gene activation. This may occur by the Notch complex synergizing with other transcription factors bound to the promoter. Alternatively, nuclear MAM separate from NICD may synergize with additional transcription factor complexes. Previous results suggest that MAM is targeted for a ubiquitination-dependent degradation pathway that is separate from NICD degradation. ${ }^{2}$ This implies that MAM is involved in functional mechanisms outside its role of target gene activation with NICD and CBF1. Further studies are required to determine MAM's role with other transcription activation complexes.

${ }^{2}$ M. Farshbaf and J.B. White, unpublished data 

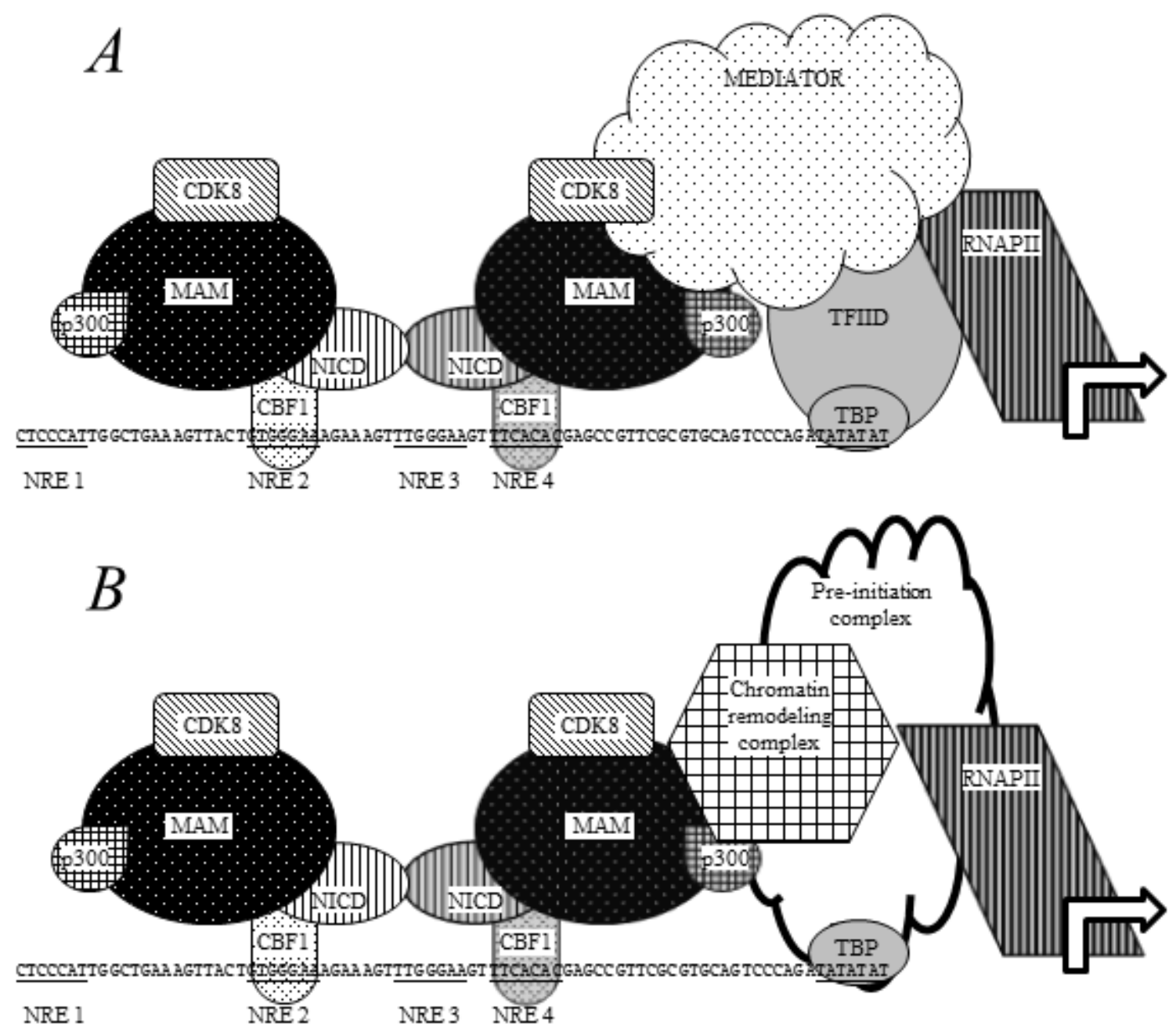

FIGURE 14: Proposed models of MAM-dependent Notch target gene activation. The Notch complexes dimerize through the ANK domain of NICD and assemble on the SPS of the gene promoter. The TFIID complex is bound to the TATA box through TBP. $A$, MAM recruits CDK8, which may recruit the Mediator core complex. Mediator can interact with TFIID and recruit RNAPII. $B$, MAM recruits $\mathrm{p} 300$, which may recruit a complex with the ability to remodel chromatin to an open conformation. This can allow the pre-initiation complex to assemble on TBP in order to recruit RNAPII. 


\section{REFERENCES}

1. Kopan, R. (2012) Notch signaling. Cold Spring Harb. Perspect. Biol. 4, 10.1101/cshperspect.a011213

2. De Strooper, B., Annaert, W., Cupers, P., Saftig, P., Craessaerts, K., Mumm, J. S., Schroeter, E. H., Schrijvers, V., Wolfe, M. S., Ray, W. J., Goate, A., and Kopan, R. (1999) A presenilin-1-dependent gamma-secretase-like protease mediates release of Notch intracellular domain. Nature 398, 518-522

3. Bray, S. J. (2006) Notch signalling: a simple pathway becomes complex. Nat. Rev. Mol. Cell Biol. 7, 678-689

4. Kovall, R. A., and Hendrickson, W. A. (2004) Crystal structure of the nuclear effector of Notch signaling, CSL, bound to DNA. EMBO J. 23, 3441-3451

5. Fryer, C. J., Lamar, E., Turbachova, I., Kintner, C., and Jones, K. A. (2002) Mastermind mediates chromatin-specific transcription and turnover of the Notch enhancer complex. Genes Dev. 16, 1397-1411

6. Fryer, C. J., White, J. B., and Jones, K. A. (2004) Mastermind recruits CycC:CDK8 to phosphorylate the Notch ICD and coordinate activation with turnover. Mol. Cell 16, 509520

7. Jarriault, S., Brou, C., Logeat, F., Schroeter, E. H., Kopan, R., and Israel, A. (1995) Signalling downstream of activated mammalian Notch. Nature 377, 355-358

8. Ong, C. T., Cheng, H. T., Chang, L. W., Ohtsuka, T., Kageyama, R., Stormo, G. D., and Kopan, R. (2006) Target selectivity of vertebrate notch proteins. Collaboration between discrete domains and CSL-binding site architecture determines activation probability. J. Biol. Chem. 281, 5106-5119

9. Nam, Y., Sliz, P., Pear, W. S., Aster, J. C., and Blacklow, S. C. (2007) Cooperative assembly of higher-order Notch complexes functions as a switch to induce transcription. Proc. Natl. Acad. Sci. U.S.A. 104, 2103-2108 
10. Liu, X., Bushnell, D. A., and Kornberg, R. D. (2013) RNA polymerase II transcription: structure and mechanism. Biochim. Biophys. Acta. 1829, 2-8

11. Arnett, K. L., Hass, M., McArthur, D. G., Ilagan, M. X., Aster, J. C., Kopan, R., and Blacklow, S.C. (2010) Structural and mechanistic insights into cooperative assembly of dimeric Notch transcription complexes. Nat. Struct. Mol. Biol. 17, 1312-1317

12. Dexter, J. (1914) The Analysis of a Case of Continuous Variation in Drosophila by a Study of Its Linkage Relations. The American Naturalist 48, 712-758

13. South, A. P., Cho, R. J., and Aster, J. C. (2012) The double-edged sword of Notch signaling in cancer. Semin. Cell Dev. Biol. 23, 458-464

14. Ellisen, L. W., Bird, J., West, D. C., Soreng, A. L., Reynolds, T. C., Smith, S. D., and Sklar, J. (1991) TAN-1, the human homolog of the Drosophila notch gene, is broken by chromosomal translocations in T lymphoblastic neoplasms. Cell 66, 649-661

15. Simmons, M. J., Serra, R., Hermance, N., and Kelliher, M. A. (2012) NOTCH1 inhibition in vivo results in mammary tumor regression and reduced mammary tumorsphere-forming activity in vitro. Breast Cancer Res. 14, R126

16. Joutel, A., Corpechot, C., Ducros, A., Vahedi, K., Chabriat, H., Mouton, P., Alamowitch, S., Domenga, V., Cecillion, M., Marechal, E., Maciazek, J., Vayssiere, C., Cruaud, C., Cabanis, E. A., Ruchoux, M. M., Weissenbach, J., Bach, J. F., Bousser, M. G., and Tournier-Lasserve, E. (1996) Notch3 mutations in CADASIL, a hereditary adultonset condition causing stroke and dementia. Nature 383, 707-710

17. Berezovska, O., Frosch, M., McLean, P., Knowles, R., Koo, E., Kang, D., Shen, J., Lu, F. M., Lux, S. E., Tonegawa, S., and Hyman, B. T. (1999) The Alzheimer-related gene presenilin 1 facilitates notch 1 in primary mammalian neurons. Brain Res. Mol. Brain Res. 69, 273-280

18. Okajima, T., Xu, A., Lei, L., and Irvine, K. D. (2005) Chaperone activity of protein O-fucosyltransferase 1 promotes notch receptor folding. Science 307, 1599-1603 
19. Logeat, F., Bessia, C., Brou, C., LeBail, O., Jarriault, S., Seidah, N. G., and Israel, A. (1998) The Notch1 receptor is cleaved constitutively by a furin-like convertase. Proc.

Natl. Acad. Sci. U.S.A. 95, 8108-8112

20. Blaumueller, C. M., Qi, H., Zagouras, P., and Artavanis-Tsakonas, S. (1997)

Intracellular cleavage of Notch leads to a heterodimeric receptor on the plasma membrane. Cell 90, 281-291

21. Sanchez-Irizarry, C., Carpenter, A. C., Weng, A. P., Pear, W. S., Aster, J. C., and Blacklow, S. C. (2004) Notch subunit heterodimerization and prevention of ligandindependent proteolytic activation depend, respectively, on a novel domain and the LNR repeats. Mol. Cell. Biol. 24, 9265-9273

22. Micchelli, C. A., Rulifson, E. J., and Blair, S. S. (1997) The function and regulation of cut expression on the wing margin of Drosophila: Notch, Wingless and a dominant negative role for Delta and Serrate. Development 124, 1485-1495

23. Munro, S., and Freeman, M. (2000) The notch signalling regulator fringe acts in the Golgi apparatus and requires the glycosyltransferase signature motif DXD. Curr. Biol. 10, $813-820$

24. Brou, C., Logeat, F., Gupta, N., Bessia, C., LeBail, O., Doedens, J. R., Cumano, A., Roux, P., Black, R. A., and Israel, A. (2000) A novel proteolytic cleavage involved in Notch signaling: the role of the disintegrin-metalloprotease TACE. Mol. Cell 5, 207-216

25. Schroeter, E. H., Kisslinger, J. A., and Kopan, R. (1998) Notch-1 signalling requires ligand-induced proteolytic release of intracellular domain. Nature 393, 382-386

26. Vasquez-Del Carpio, R., Kaplan, F. M., Weaver, K. L., VanWye, J. D., Alves-Guerra, M. C., Robbins, D. J., and Capobianco, A. J. (2011) Assembly of a Notch transcriptional activation complex requires multimerization. Mol. Cell. Biol. 31, 1396-1408

27. Zhou, S., Fujimuro, M., Hsieh, J. J., Chen, L., Miyamoto, A., Weinmaster, G., and Hayward, S. D. (2000) SKIP, a CBF1-associated protein, interacts with the ankyrin repeat domain of NotchIC to facilitate NotchIC function. Mol. Cell. Biol. 20, 2400-2410 
28. Yamamoto, S., Charng, W. L., Rana, N. A., Kakuda, S., Jaiswal, M., Bayat, V., Xiong, B., Zhang, K., Sandoval, H., David, G., Wang, H., Haltiwanger, R. S., and Bellen, H. J. (2012) A mutation in EGF repeat-8 of Notch discriminates between Serrate/Jagged and Delta family ligands. Science 338, 1229-1232

29. Aster, J. C., Xu, L., Karnell, F. G., Patriub, V., Pui, J. C., and Pear, W. S. (2000) Essential roles for ankyrin repeat and transactivation domains in induction of T-cell leukemia by notch1. Mol. Cell. Biol. 20, 7505-7515

30. Kurooka, H., Kuroda, K., and Honjo, T. (1998) Roles of the ankyrin repeats and Cterminal region of the mouse notch1 intracellular region. Nucleic Acids Res. 26, 54485455

31. Kao, H. Y., Ordentlich, P., Koyano-Nakagawa, N., Tang, Z., Downes, M., Kintner, C. R., Evans, R. M., and Kadesch, T. (1998) A histone deacetylase corepressor complex regulates the Notch signal transduction pathway. Genes Dev. 12, 2269-2277

32. Hsieh, J. J., Zhou, S., Chen, L., Young, D. B., and Hayward, S. D. (1999) CIR, a corepressor linking the DNA binding factor CBF1 to the histone deacetylase complex. Proc. Natl. Acad. Sci. U.S.A. 96, 23-28

33. Oswald, F., Kostezka, U., Astrahantseff, K., Bourteele, S., Dillinger, K., Zechner, U., Ludwig, L., Wilda, M., Hameister, H., Knochel, W., Liptay, S., and Schmid, R. M. (2002) SHARP is a novel component of the Notch/RBP-Jkappa signalling pathway. EMBO J. 21, 5417-5426

34. Zhou, S., and Hayward, S. D. (2001) Nuclear localization of CBF1 is regulated by interactions with the SMRT corepressor complex. Mol. Cell. Biol. 21, 6222-6232

35. Wilson, J. J., and Kovall, R. A. (2006) Crystal structure of the CSL-NotchMastermind ternary complex bound to DNA. Cell 124, 985-996

36. Friedmann, D. R., Wilson, J. J., and Kovall, R. A. (2008) RAM-induced allostery facilitates assembly of a notch pathway active transcription complex. J. Biol. Chem. 283, 14781-14791 
37. Petcherski, A. G., and Kimble, J. (2000) Mastermind is a putative activator for Notch. Curr. Biol. 10, R471-3

38. Wu, L., Sun, T., Kobayashi, K., Gao, P., and Griffin, J. D. (2002) Identification of a family of mastermind-like transcriptional coactivators for mammalian notch receptors. Mol. Cell. Biol. 22, 7688-7700

39. Nam, Y., Sliz, P., Song, L., Aster, J. C., and Blacklow, S. C. (2006) Structural basis for cooperativity in recruitment of MAML coactivators to Notch transcription complexes. Cell 124, 973-983

40. Wallberg, A. E., Pedersen, K., Lendahl, U., and Roeder, R. G. (2002) p300 and PCAF act cooperatively to mediate transcriptional activation from chromatin templates by notch intracellular domains in vitro. Mol. Cell. Biol. 22, 7812-7819

41. Herzig, S., Hedrick, S., Morantte, I., Koo, S. H., Galimi, F., and Montminy, M. (2003) CREB controls hepatic lipid metabolism through nuclear hormone receptor PPAR-gamma. Nature 426, 190-193

42. Popko-Scibor, A. E., Lindberg, M. J., Hansson, M. L., Holmlund, T., and Wallberg, A. E. (2011) Ubiquitination of Notch1 is regulated by MAML1-mediated p300 acetylation of Notch1. Biochem. Biophys. Res. Commun. 416, 300-306

43. Wu, G., Lyapina, S., Das, I., Li, J., Gurney, M., Pauley, A., Chui, I., Deshaies, R. J., and Kitajewski, J. (2001) SEL-10 is an inhibitor of notch signaling that targets notch for ubiquitin-mediated protein degradation. Mol. Cell. Biol. 21, 7403-7415

44. Oberg, C., Li, J., Pauley, A., Wolf, E., Gurney, M., and Lendahl, U. (2001) The Notch intracellular domain is ubiquitinated and negatively regulated by the mammalian Sel-10 homolog. J. Biol. Chem. 276, 35847-35853

45. Vannini, A., and Cramer, P. (2012) Conservation between the RNA polymerase I, II, and III transcription initiation machineries. Mol. Cell 45, 439-446 
46. Mathis, D. J., and Chambon, P. (1981) The SV40 early region TATA box is required for accurate in vitro initiation of transcription. Nature 290, 310-315

47. Kornberg, R. D. (2005) Mediator and the mechanism of transcriptional activation. Trends Biochem. Sci. 30, 235-239

48. Mittler, G., Kremmer, E., Timmers, H. T., and Meisterernst, M. (2001) Novel critical role of a human Mediator complex for basal RNA polymerase II transcription. EMBO Rep. 2, 808-813

49. Bourbon, H. M. (2008) Comparative genomics supports a deep evolutionary origin for the large, four-module transcriptional mediator complex. Nucleic Acids Res. 36, 39934008

50. Lariviere, L., Geiger, S., Hoeppner, S., Rother, S., Strasser, K., and Cramer, P. (2006) Structure and TBP binding of the Mediator head subcomplex Med8-Med18-Med20. Nat. Struct. Mol. Biol. 13, 895-901

51. Esnault, C., Ghavi-Helm, Y., Brun, S., Soutourina, J., Van Berkum, N., Boschiero, C., Holstege, F., and Werner, M. (2008) Mediator-dependent recruitment of TFIIH modules in preinitiation complex. Mol. Cell 31, 337-346

52. Sakurai, H., and Fukasawa, T. (2003) Artificial recruitment of certain Mediator components affects requirement of basal transcription factor IIE. Genes Cells 8, 41-50

53. Acevedo, M. L., and Kraus, W. L. (2003) Mediator and p300/CBP-steroid receptor coactivator complexes have distinct roles, but function synergistically, during estrogen receptor alpha-dependent transcription with chromatin templates. Mol. Cell. Biol. 23, $335-348$

54. Black, J. C., Choi, J. E., Lombardo, S. R., and Carey, M. (2006) A mechanism for coordinating chromatin modification and preinitiation complex assembly. Mol. Cell 23, 809-818 
55. Pavri, R., Lewis, B., Kim, T. K., Dilworth, F. J., Erdjument-Bromage, H., Tempst, P., de Murcia, G., Evans, R., Chambon, P., and Reinberg, D. (2005) PARP-1 determines specificity in a retinoid signaling pathway via direct modulation of mediator. Mol. Cell 18, 83-96

56. Elmlund, H., Baraznenok, V., Lindahl, M., Samuelsen, C. O., Koeck, P. J., Holmberg, S., Hebert, H., and Gustafsson, C. M. (2006) The cyclin-dependent kinase 8 module sterically blocks Mediator interactions with RNA polymerase II. Proc. Natl. Acad. Sci. U.S.A. 103, 15788-15793

57. Wang, G., Balamotis, M. A., Stevens, J. L., Yamaguchi, Y., Handa, H., and Berk, A. J. (2005) Mediator requirement for both recruitment and postrecruitment steps in transcription initiation. Mol. Cell 17, 683-694

58. Fromm, M., and Berg, P. (1983) Simian virus 40 early- and late-region promoter functions are enhanced by the 72-base-pair repeat inserted at distant locations and inverted orientations. Mol. Cell. Biol. 3, 991-999

59. Lettice, L. A., Heaney, S. J., Purdie, L. A., Li, L., de Beer, P., Oostra, B. A., Goode, D., Elgar, G., Hill, R. E., and de Graaff, E. (2003) A long-range Shh enhancer regulates expression in the developing limb and fin and is associated with preaxial polydactyly. Hum. Mol. Genet. 12, 1725-1735

60. Englesberg, E., Squires, C., and Meronk, F.,Jr (1969) The L-arabinose operon in Escherichia coli B-r: a genetic demonstration of two functional states of the product of a regulator gene. Proc. Natl. Acad. Sci. U.S.A. 62, 1100-1107

61. Bulger, M., and Groudine, M. (2011) Functional and mechanistic diversity of distal transcription enhancers. Cell 144, 327-339

62. Sasai, Y., Kageyama, R., Tagawa, Y., Shigemoto, R., and Nakanishi, S. (1992) Two mammalian helix-loop-helix factors structurally related to Drosophila hairy and Enhancer of split. Genes Dev. 6, 2620-2634 
63. Blackwell, T. K., and Weintraub, H. (1990) Differences and similarities in DNAbinding preferences of $\mathrm{MyOD}$ and $\mathrm{E} 2 \mathrm{~A}$ protein complexes revealed by binding site selection. Science 250, 1104-1110

64. Kageyama, R., Ohtsuka, T., and Tomita, K. (2000) The bHLH gene Hes1 regulates differentiation of multiple cell types. Mol. Cells 10, 1-7

65. Ishibashi, M., Ang, S. L., Shiota, K., Nakanishi, S., Kageyama, R., and Guillemot, F. (1995) Targeted disruption of mammalian hairy and Enhancer of split homolog-1 (HES1) leads to up-regulation of neural helix-loop-helix factors, premature neurogenesis, and severe neural tube defects. Genes Dev. 9, 3136-3148

66. Jensen, J., Pedersen, E. E., Galante, P., Hald, J., Heller, R. S., Ishibashi, M., Kageyama, R., Guillemot, F., Serup, P., and Madsen, O. D. (2000) Control of endodermal endocrine development by Hes-1. Nat. Genet. 24, 36-44

67. Hirata, H., Yoshiura, S., Ohtsuka, T., Bessho, Y., Harada, T., Yoshikawa, K., and Kageyama, R. (2002) Oscillatory expression of the bHLH factor Hes1 regulated by a negative feedback loop. Science 298, 840-843

68. Feder, J. N., Li, L., Jan, L. Y., and Jan, Y. N. (1994) Genomic cloning and chromosomal localization of HRY, the human homolog to the Drosophila segmentation gene, hairy. Genomics 20, 56-61

69. Takebayashi, K., Sasai, Y., Sakai, Y., Watanabe, T., Nakanishi, S., and Kageyama, R. (1994) Structure, chromosomal locus, and promoter analysis of the gene encoding the mouse helix-loop-helix factor HES-1. Negative autoregulation through the multiple $\mathrm{N}$ box elements. J. Biol. Chem. 269, 5150-5156

70. Nellesen, D. T., Lai, E. C., and Posakony, J. W. (1999) Discrete enhancer elements mediate selective responsiveness of enhancer of split complex genes to common transcriptional activators. Dev. Biol. 213, 33-53

71. Cave, J. W., Loh, F., Surpris, J. W., Xia, L., and Caudy, M. A. (2005) A DNA transcription code for cell-specific gene activation by notch signaling. Curr. Biol. 15, 94104 
72. Wu, L., Aster, J. C., Blacklow, S. C., Lake, R., Artavanis-Tsakonas, S., and Griffin, J. D. (2000) MAML1, a human homologue of Drosophila mastermind, is a transcriptional co-activator for NOTCH receptors. Nat. Genet. 26, 484-489

73. Kitagawa, M., Oyama, T., Kawashima, T., Yedvobnick, B., Kumar, A., Matsuno, K., and Harigaya, K. (2001) A human protein with sequence similarity to Drosophila mastermind coordinates the nuclear form of notch and a CSL protein to build a transcriptional activator complex on target promoters. Mol. Cell. Biol. 21, 4337-4346

74. Liu, F., and Posakony, J. W. (2012) Role of architecture in the function and specificity of two Notch-regulated transcriptional enhancer modules. PLoS Genet. 8, e1002796

75. Nishimura, M., Isaka, F., Ishibashi, M., Tomita, K., Tsuda, H., Nakanishi, S., and Kageyama, R. (1998) Structure, chromosomal locus, and promoter of mouse Hes2 gene, a homologue of Drosophila hairy and Enhancer of split. Genomics 49, 69-75

76. Turner, D. L., and Weintraub, H. (1994) Expression of achaete-scute homolog 3 in Xenopus embryos converts ectodermal cells to a neural fate. Genes Dev. 8, 1434-1447

77. Takebayashi, K., Akazawa, C., Nakanishi, S., and Kageyama, R. (1995) Structure and promoter analysis of the gene encoding the mouse helix-loop-helix factor HES-5. Identification of the neural precursor cell-specific promoter element. J. Biol. Chem. 270, $1342-1349$

78. Bland, J. M., and Altman, D. G. (1995) Multiple significance tests: the Bonferroni method. BMJ 310, 170

79. Perneger, T. V. (1998) What's wrong with Bonferroni adjustments. BMJ 316, 12361238

80. Kiran, K., Ansari, S. A., Srivastava, R., Lodhi, N., Chaturvedi, C. P., Sawant, S. V., and Tuli, R. (2006) The TATA-box sequence in the basal promoter contributes to determining light-dependent gene expression in plants. Plant Physiol. 142, 364-376 
81. Aster, J. C., and Blacklow, S. C. (2012) Targeting the Notch pathway: twists and turns on the road to rational therapeutics. J. Clin. Oncol. 30, 2418-2420

82. Zhu, Q., Dabi, T., and Lamb, C. (1995) TATA box and initiator functions in the accurate transcription of a plant minimal promoter in vitro. Plant Cell 7, 1681-1689

83. Ren, D., Nedialkov, Y. A., Li, F., Xu, D., Reimers, S., Finkelstein, A., and Burton, Z. F. (2005) Spacing requirements for simultaneous recognition of the adenovirus major late promoter TATAAAAG box and initiator element. Arch. Biochem. Biophys. 435, 347-362

84. Yao, T. P., Ku, G., Zhou, N., Scully, R., and Livingston, D. M. (1996) The nuclear hormone receptor coactivator SRC-1 is a specific target of p300. Proc. Natl. Acad. Sci. U.S.A. 93, 10626-10631

85. Gerritsen, M. E., Williams, A. J., Neish, A. S., Moore, S., Shi, Y., and Collins, T. (1997) CREB-binding protein/p300 are transcriptional coactivators of p65. Proc. Natl. Acad. Sci. U.S.A. 94, 2927-2932

86. Huang, S. S., Clarke, D. C., Gosline, S. J., Labadorf, A., Chouinard, C. R., Gordon, W., Lauffenburger, D. A., and Fraenkel, E. (2013) Linking proteomic and transcriptional data through the interactome and epigenome reveals a map of oncogene-induced signaling. PLoS Comput. Biol. 9, e1002887 